\title{
A holistic planning model for sustainable water management in the shale gas industry
}

\author{
Alba Carrero-Parreño ${ }^{a}$, Juan A. Reyes-Labarta*a,b, Raquel Salcedo-Díaz ${ }^{a, b}$, Rubén Ruiz- \\ Femenia $^{a, b}$, Viviani C. Onishi ${ }^{a}$, José A. Caballero ${ }^{\mathrm{a}, b}$, Ignacio E. Grossmann ${ }^{\mathrm{c}}$ \\ ${ }^{a}$ Institute of Chemical Process Engineering, University of Alicante, Ap Correos 99, \\ Alicante 03080, Spain \\ ${ }^{b}$ Department of Chemical Engineering, University of Alicante, Ap Correos 99, Alicante \\ 03080, Spain \\ ${ }^{c}$ Department of Chemical Engineering, Carnegie Mellon University, Pittsburgh, PA \\ 15213, U.S.A. \\ * Corresponding author at. Institute of Chemical Process Engineering, University of \\ Alicante, Ap Correos 99, Alicante 03080,Spain.Phone: +34 965903867.ja.reyes@ua.es
}

\section{ABSTRACT}

To address water planning decisions in shale gas operations, we present a novel water management optimization model that explicitly takes into account the effect of high concentration of total dissolved solids (TDS), and its temporal variation in the impaired water. The model comprises different water management strategies: a) direct wastewater reuse, which is possible due to the new additives tolerant to high TDS concentration but at the expense of increasing the costs; b) wastewater treatment, taking separately into account pre-treatments, softening and desalination technologies and c) send to Class II disposal sites.

The objective is to maximize the "sustainability profit" determining flowback destination (reuse, degree of treatment or disposal), the fracturing schedule, fracturing fluid composition and the number of water storage tanks needed at each period of time.

Due to the rigorous determination of TDS in all water streams, the model is a non-convex MINLP model that is tackled in two steps: first, an MILP model is solved based on McCormick relaxations; next, the binary variables that determine the fracturing schedule are fixed, and a smaller MINLP is solved. 
33 Finally, several case studies based on Marcellus Shale play are optimized to illustrate the

34 effectiveness of the proposed formulation. The model identifies the best water management option to improve both economic and environmental criteria, resulting to be direct reuse the best one.

Keywords: water management, optimization, MINLP, planning, shale gas

\section{INTRODUCTION}

The global natural gas production is expected to increase around $62 \%$ by 2040 . The

40 largest component in the projected growth is due to shale gas production, which will 41 increase from 342 billion cubic feet per day (bcf/d) in 2015 to 554 bcf/d by $2040 .^{1}$

42 Currently, only the United States, Canada, China, and Argentina have commercial shale gas production. However, Mexico and Algeria are expected to contribute to the projected growth due to the technological improvements made in the extraction techniques. ${ }^{1,2}$

It is well-known that the extraction of shale gas, apart from generating huge benefits, has associated environmental risks including many water-based concerns. The exploitation stages of a shale well include exploration, wellpad construction, well drilling, well treatment and completion, and production. The largest volume of water used is during well treatment and completion phase, when hydraulic fracturing occurs. Operators

50 fracture shale gas wells in 8 to 23 stages, using from 190 to $38,000 \mathrm{~m}^{3}$ of fracturing fluid per well depending on shale gas formation. ${ }^{3}$ Fracturing fluid typically contains about $90 \%$ water, $9 \%$ propping agents and less than $1 \%$ of friction-reducing additives. ${ }^{3,4}$ After a well is hydraulically fractured, the pressure of the wellhead is released allowing a portion of 54 wastewater, called flowback water, return to the wellhead. Flowback water is recovered 55 from few days to few weeks, containing total dissolved solids (TDS) ranging from 10,000

56 to $150,000 \mathrm{mg} \mathrm{L}^{-1}$. The wastewater that continues generating over the life of the well (10 $57-30$ years) is called produced water. The TDS concentration in long-term produced water 
A. Carrero-Parreño et al.

can reach $250,000 \mathrm{mg} \mathrm{L}^{-1}$. Both wastewater volume and concentration of TDS are uncertain and vary with the geographical properties of the formation. As a rule of thumb, the volume of wastewater generated is 50 percent flowback water and 50 percent produced water. $^{3}$

Current water management strategies include disposal of wastewater via Class II disposal wells, transfer to a centralized water treatment facility $(\mathrm{CWT})$ or to mobile desalination treatment, or direct reuse in drilling the subsequent wells. The reused flowback is called impaired water.

Mechanical vapor compression is the most common and well-established desalination treatment employed in shale gas industry. ${ }^{5-7}$ Besides, the emerging membrane distillation technology is gaining importance in the last years for desalinating shale water due to the utilization of low-grade heat sources for separating salts from water. ${ }^{6-8}$

Direct reuse of flowback water has been possible due to the development of salt-tolerant friction reducers. ${ }^{3,9,10}$ Previous friction reducers were not compatible with salt-water, therefore they were not able to control friction pressure losses and associated pump pressure. Direct reuse in drilling the subsequent wells is currently the most popular option due to its operational simplicity for contractors. ${ }^{11}$ Moreover, this practice has the potential to decrease the environmental issues associated with shale gas water management such as transportation, disposal or treatment. However, friction reducers expenses increase with the concentration of TDS. Operators must take into consideration that reusing impaired water, the concentration of TDS will increase over the time representing a major cost-barrier.

A rapid increase in publications on water management optimization in shale gas industry has been reported in the recent years. These publications cover various topics, including 
environmental impacts and uncertainty analysis in freshwater availability or flowback water production to identify its impact on the optimal decisions.

84 Yang et. al ${ }^{12}$ proposed a discrete-time two-stage stochastic mixed-integer linear programming model to determine - in short-term operations - the optimal fracturing schedule and cost of transportation, storage, treatment and disposal cost under uncertain availability water. The model does not account for TDS concentration. They developed an extended model ${ }^{13}$ accounting for TDS to consider long-term decisions for investments in water treatment, impoundments, and pipelines. However, to avoid non-linearities, they used an approximation by discretizing the TDS concentration. Bartholomew and Mauter ${ }^{14}$ used the Yang et. al model ${ }^{13}$ integrating human health and environmental impacts with multi-objective optimization. However, the authors do not consider return to pad operations and fixed the blending ratio a priori. Gao and You ${ }^{15}$ proposed a mixed-integer linear fractional programming model to maximize the profit per unit of freshwater consumption. The authors include multiple transportation modes and water management options. Nevertheless, they also do not consider return to pad operations and they fixed the blending ratio and fracturing schedule a priori. Gao and $\mathrm{You}^{16}$ also presented a mixed98 integer nonlinear programming problem addressing the life-cycle economic and environmental optimization of shale gas supply chain network. Guerra et al. ${ }^{17}$ presented an optimization framework that integrates the design and planning of the shale gas supply

101 chain and water management. In this case, the fracturing schedule and sizing of storage

102 facilities are out of the scope of the proposed framework. Moreover, they do not consider 103 reusing water directly without treatment.

104 Lira-Barragán et. $a 1^{18}$ presented a mathematical model for synthesizing shale gas water networks accounting uncertainty in water demand for hydraulic fracturing and flowback water forecast. Lira-Barragán et. $\mathrm{al}^{19}$ also developed an MILP mathematical programming 
A. Carrero-Parreño et al.

107 formulation accounting for economics by minimizing the cost for the freshwater, storage

108 treatment, disposal, and transportation, and minimizing freshwater usage and wastewater

109 discharge as an environmental objective. However, in both works, the schedule is fixed

110 in advance, and the wastewater is always treated.

111 Drouven and Grossmann ${ }^{20}$ proposed an MILP model to identify the optimal strategies for

112 impaired water overestimating the cost of friction reducers. The authors consider return

113 to pad operations and assume that the water-blending ratio is unrestricted. However, the

114 mathematical model does not take into account other water management strategies nor

115 the salt concentration of impaired water.

116 Yizhon Chen et al. ${ }^{21}$ developed a multi-level decision-making programming model for

117 planning shale gas supply chain operations. The first level focused on mitigating GHG

118 emissions, the middle level maximizes the system benefits and the lower level seeks to

119 minimize the water usage. Lately, they published two works accounting uncertainties in

120 the estimated ultimate recovery (EUR), greenhouse gas (GHG) emissions and flowback

121 and produced water production, respectively, helping stakeholder to achieve supply chain

122 satisfaction and to control GHG emissions. ${ }^{22,23}$ The fracturing schedule is out of the scope

123 of the proposed framework. Additionally, they do not include onsite-treatment option

124 either storage solution.

125 This paper focuses on overcoming some of the limitations of the previous papers cited

126 above. Specifically, we propose a holistic mixed-integer non-linear programming

127 (MINLP) model that considers the TDS concentration of flowback and impaired water,

128 as well as different water treatment solutions. The main novelties introduced in the

129 mathematical model are the estimation of friction reducers expenses, as a function of TDS

130 concentration to determine if the level of TDS in impaired water is an obstacle for reusing

131 it in drilling and fracturing operations, and the rigorous handling at storage solution by 
132 determining the required number of tanks installed/uninstalled over the period of time.

133 Additionally, the objective of the proposed model is to maximize the "sustainability

134 profit" 24 in order to obtain a compromise solution among the three pillars of sustainability:

135 social, economic, and environmental. The advantage of this metric is that multi-objective

136 optimization is concentrated to a single-objective since all the indicators are expressed in

137 monetary terms. Besides, the solution obtained is clear, understandable and intuitive for

138 the stakeholders since different elements of the objective function can be easily compared.

139 The rest of the paper is organized as follows: The problem statement is defined in section

140 2. In section 3, the mathematical MINLP model is described in detail. Section 4 describes

141 the modeling and solution strategy. The results obtained from different case studies based

142 on Marcellus shale play are presented in section 5. Finally, the last section summarizes

143 the conclusions of the present work.

\section{PROBLEM STATEMENT}

146 The problem described in this paper can be stated as follows. Given are the following:

147 - A set of shale gas wells belonging to a specific wellpads including water 148 requirements, fracturing time and crews available to perform the drilling and 149 completion phase. Profiles for the flowback flowrate, TDS concentration and gas $150 \quad$ production curve per well are also provided.

151 - The capacity and the maximum number of fracturing tanks. Each storage unit 152 includes the cost associated to move, demobilize and clean out the tank before 153 removing it from the location and leasing cost.

154 - The capacity and the maximum number of freshwater tanks available to store the 155 water required to complete each well. 
A. Carrero-Parreño et al.

- The capacity and the maximum number of impoundments. Freshwater can also be stored in freshwater impoundments.

- A set of freshwater sources available to supply the water for hydraulic fracturing operations and the water withdrawal cost.

- A set of Class II disposal wells to inject the wastewater and the corresponding cost of disposal.

- A set of treatment technologies to desalinate the flowback water onsite. The maximum capacity, treatment cost, leasing cost and the cost associated to move, demobilize and clean out are also given.

- A set of centralized water treatment (CWT) plants and the treatment cost and maximum capacity of each facility.

- Locations of the freshwater source, centralized water treatment (CWT), disposal wells and wellpads.

- Transportation costs of freshwater and wastewater via trucks.

- The cost of moving rigs, well drilling and completion, shale gas production and friction reducers are given.

- The sales price of shale gas per week for all prospective wells is provided.

The target is to determine the number of tanks leased at each time period, the fracturing schedule (wellpad fracturing start date), flowback destination (reuse, treatment or disposal), and type and location of onsite desalination treatment at each time period.

For this purpose, a shale gas water management superstructure, shown in Figure 1, is proposed. 
A. Carrero-Parreño et al.

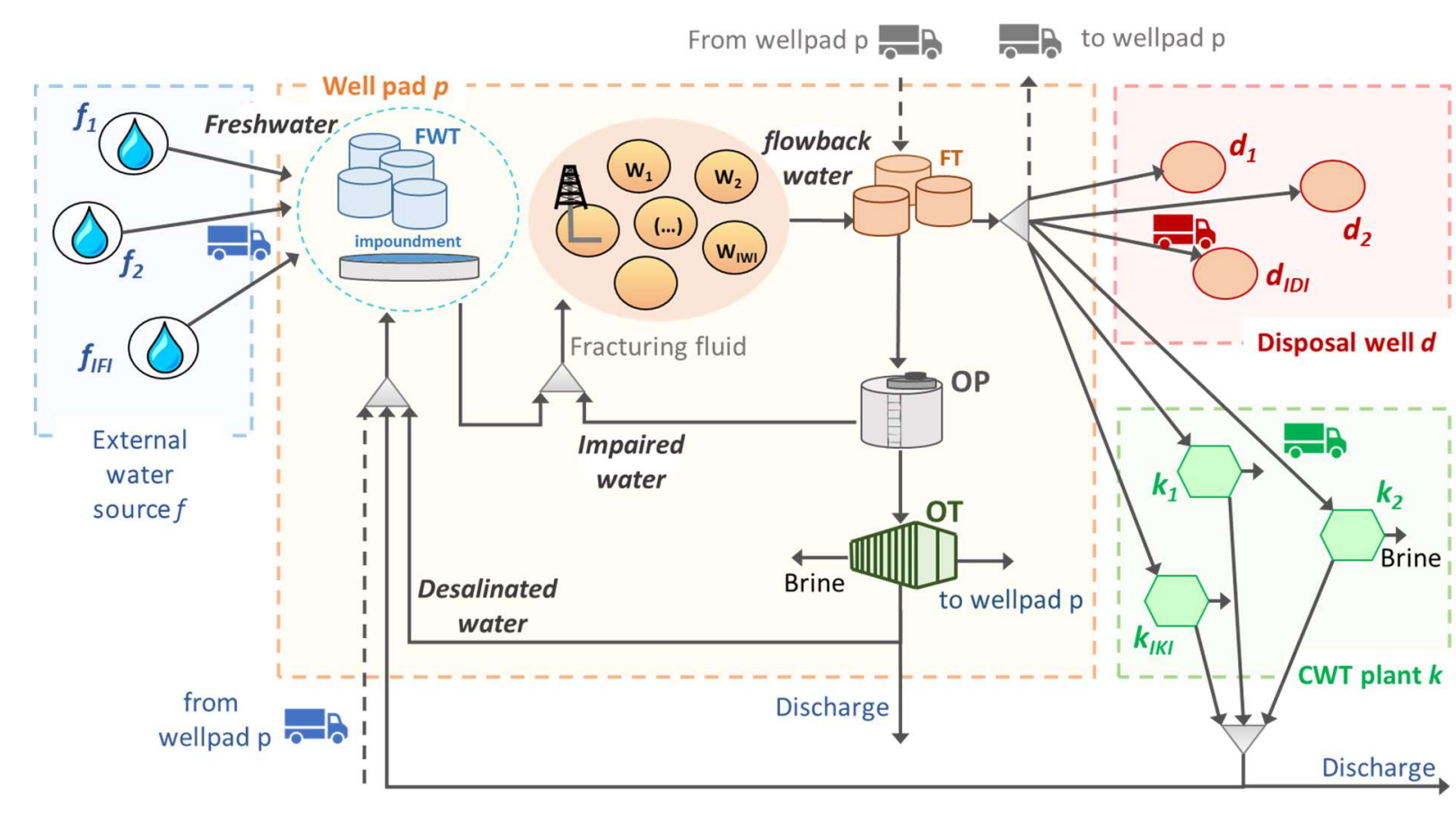

FWT: Freshwater tank / FT: Fracturing tank /OP: Onsite pre-treatment /OT: Onsite treatment

179 Figure 1. The proposed superstructure for shale gas water management operations.

181 The system comprises wellpads $p$, shale gas wells in each wellpad $w$, natural freshwater sources $f$, fracturing crew $c$, centralized water treatment technologies (CWT) $k$, and

183 disposal wells $d$.

184 As commented before, part of the water used for hydraulic fracturing returns to the

185 wellhead. This wastewater, called flowback water, is stored in portable fracturing tanks.

186 After that, flowback water can be transported to a neighboring wellpad, CWT plants or

187 Class II disposal wells. Also, it can be sent to a basic mobile treatment (pre-treatment) 188 placed in each wellpad.

189 Pre-treatment can remove bacteria, suspended solids, oil and grease and certain ions

190 depending on the final destination. ${ }^{25}$ The pretreated water can be desalinated in onsite

191 desalination units or can be used to fracture others wells in the same wellpad.

192 Mobile desalination treatment can be used two different technologies -membrane 193 distillation (MD) ${ }^{26}$ and/or multi-effect evaporation with mechanical vapor recompression 
A. Carrero-Parreño et al.

194 (MEE-MVR) ${ }^{5,27}$ - to remove TDS contents. We consider that these technologies are

195 designed to obtain the brine stream close to salt saturation conditions to maximize, at the

196 same time, the freshwater recovered. Treatment cost restricts the selection of the

197 desalination technology. Desalinated water from onsite treatment or CWT facility can be

198 used as a fracturing fluid or discharged - after adequate water conditioning- for other

199 uses. Freshwater is withdrawal from uninterruptible freshwater sources. This water,

200 together with desalinated water, is stored in water impoundment and/or freshwater tanks

201 (FWT).

202 The assumptions made in this work are as follows:

- A fixed time horizon is discretized into weeks as time intervals.

- The volume of water required to fracture each well is available at the beginning of well development, and includes the water used in drilling, construction and completion.

- Onsite pretreatment $(\mathrm{OP})$ process provides adequate contaminant removal for the next operations.

- Friction reducers costs increase linearly with the concentration of salts.

- Transportation is only performed by trucks.

\section{MATHEMATICAL PROGRAMMING MODEL}

213 The optimization water management problem, which is detailed below, is formulated as

214 an MINLP model that comprises: material balance in storage tanks, assignment

215 constraints, logic constraints, mixers and splitters, and an objective function. Note that

216 lower-case letters are used for variables and upper-case letters and Greek letters for

217 parameters.

218 
A. Carrero-Parreño et al.

220 To develop the mathematical model, the following sets are defined.

221

$$
\begin{aligned}
& P=\{p / p \text { is a wellpad }\} \\
& W=\{w / w \text { is a well }\} \\
& T=\{t / t \text { is a time period }\} \\
& N=\{n / n \text { is a onsite water treatment }\} \\
& K=\{k / k \text { is centralized water treatment plant }\} \\
& F=\{f / f \text { is a freshwater source }\} \\
& C=\{c / c \text { is a fracturing crew }\} \\
& D=\{d / d \text { is a disposal }\} \\
& S=\{s / s \text { is a storage tank type }\} \\
& R P W_{p}=\{w / w \text { is a well in wellpad } p\}
\end{aligned}
$$

\section{Assignment constraint}

223 Eq. (1) guarantees that at the time horizon each well can only be drilled once by one of

224 the available fracturing crew $c$,

$225 \quad \sum_{t \in T} \sum_{c \in C} y_{t, p, w, c}^{h f} \leq 1 \quad \forall w \in R P W_{p}, p \in P$

226 where $y_{t, p, w, c}^{h f}$ indicates that the well $w$ in wellpad $p$ is stimulating by fracturing crew $c$ in

227 time period $t$.

228 Eq. (2) ensures that there is no overlap in drilling and completions operations between

229 different wells, namely, a fracturing crew cannot begin to fracture a new well until it has

230 finished fracturing the previous one,

$231 \sum_{p \in P} \sum_{w \in R P W_{p}} \sum_{t t=t-\tau_{w}+1}^{t} y_{t t, p, w, c}^{h f} \leq 1 \quad \forall t \in T, c \in C$

232 where $\tau_{w}$ is a parameter that indicates the time required to fracture well $w$ by fracturing 233 crew $c$.

234 Shale water composition and water recovered 
A. Carrero-Parreño et al.

235 After a well is drilled and hydraulically fractured, a portion of the water injected is

236 returned to the wellhead. Well drilling and construction typically take from one to five

237 weeks ${ }^{3}$, therefore the flowback water will come out $\tau_{\mathrm{w}}$ weeks after a well is selected to be

238 fractured,

$239 \sum_{c \in C} y_{t, p, w, c}^{h f}=y_{t+\tau_{w}, p, w}^{f b} \quad t \leq T-\tau_{w}, \forall w \in R P W_{p}, p \in P$

240 where $y_{t, p, w, c}^{f b}$ represents the time period when the flowback water comes out. The binary

241 variable $y_{t, p, w, c}^{f b}$ is treated as a continuous variable -with bounds between 0 and 1- since

242 its integrality is enforced by constraint (3). This practice permits save time and resources

243 due to any binary (integer) variable will eventually could be branched during the

244 optimization. Although in modern MI(N)LP solvers this situation is somewhat minimized

245 due to constraint propagation techniques, more rigorous selection of branching variables,

246 etc., it could still have an important effect on solver performance.

247 The shale gas water recovered and composition from each wellpad, once the well is

248 hydraulically fractured, is calculated with Eqs. (4-5),

$249 \quad f_{t, p, w}^{\text {well }}=\sum_{t t=0}^{t t \leq t-1} F_{t-t t, p, w}^{\text {well }} \cdot y_{t t+1, p, w}^{f b} \quad \forall t \in T, w \in R P W_{p}, p \in P$

$250 \quad c_{t, p, w}^{\text {well }}=\sum_{t t=0}^{t t \leq t-1} C_{t-t t, p, w}^{w e l l} \cdot y_{t t+1, p, w}^{f b} \quad \forall t \in T, w \in R P W_{p}, p \in P$

251 where, $F_{t, p, w}^{w e l l}$ and $C_{t, p, w}^{w e l l}$ are parameters that indicate flowback flowrate and TDS

252 concentration, respectively.

253 Eqs. (6-7) correspond to the mass and salt balance of flowback water collected from the

254 wells belonging the wellpad $p$,

255

$f_{t, p}^{p a d}=\sum_{w \in R P W_{p}} f_{t, p, w}^{w e l l} \quad \forall t \in T, p \in P$ 
A. Carrero-Parreño et al.

$$
c_{t, p}^{p a d} \cdot f_{t, p}^{p a d}=\sum_{w \in R P W_{p}} C_{t, p, w}^{w e l l} \cdot F_{t, p, w}^{\text {well }} \quad \forall t \in T, p \in P
$$

\section{Mass and salt balance in storage tanks}

258 The level of the storage tank in each time period $\left(s t_{t, p, s}\right)$ depends on the water stored in

259 the previous time period $\left(s t_{t-1, p, s}\right)$, the mass flowrates of the inlet streams belonging to

260 the storage tank s $\left(f_{t, p, s}^{i}\right)$, and the mass flowrates of the outlet streams belonging to the

261 storage tank $s\left(f_{t, p, s}^{o}\right)$. Note that subsets ISs and OSs represent the set of inlet and outlet

262 streams that belong storage tank s.

$$
s t_{t-1, p, s}+\sum_{i \in I S_{s}} f_{t, p, s}^{i}=s t_{t, p, s}+\sum_{o \in O S_{s}} f_{t, p, s}^{o} \quad \forall t \in T, p \in P, s \in S
$$

264 The salt mass balance in fracturing tank (FT) is described by the following equation,

$$
\begin{aligned}
& s t_{t-1, p, s} \cdot c_{t-1, p}+\sum_{i \in I S} f_{t, p, s}^{i} \cdot c_{t, p}^{i}=\left(s t_{t, p, s}+\sum_{o \in O S} f_{t, p, s}^{o}\right) \cdot c_{t, p} \\
& \forall t \in T, p \in P, s \in\{f t\}
\end{aligned}
$$

\section{Storage balances}

267 Flowback water and freshwater are stored in portable leased tanks at wellpad $p$. Eq. (10)

268 describes the storage balance of tank $s$ in wellpad $p$ in time period $t$,

$$
n_{t, p, s}=n_{t-1, p, s}+n_{t, p, s}^{i n s}-n_{t, p, s}^{u n i n s} \quad \forall t \in T, p \in P, s \in S
$$

270 where $n_{t, p, s}$ is the total number of tanks, $n_{t, p, s}^{\text {ins }}$ and $n_{t, p, s}^{\text {unins }}$ represent the number of

271 installed or uninstalled tanks in a specific time period.

272 The amount of water stored, $s t_{t, p, s}$, is bounded by the capacity of one tank, $C S T_{s}$, and 273 the number of tanks installed, $n_{t, p, s}$. Besides, the storage tanks should handle the 274 wastewater that returns to the wellhead from one day. Therefore, as the time horizon is 275 discretized into weeks, the variable $\theta_{t, p, s}$, which is equal to the inlet wastewater or 
A. Carrero-Parreño et al.

276 freshwater divided by the number of days in a week, is introduced to avoid oversizing the

277 tanks,

$278 \quad s t_{t, p, s}+\theta_{t, p, s} \leq C S T_{s} \cdot n_{t, p, s} \quad \forall t \in T, p \in P, s \in\{f t\}$

$$
N_{s}^{L O} \cdot y_{t, p, s}^{s t} \leq n_{t, p, s}^{i n s} \leq N_{s}^{U P} \cdot y_{t, p, s}^{s t} \quad \forall t \in T, p \in P, s \in S
$$

$280 N_{S}^{L O}$ and $N_{S}^{U P}$ are lower and upper bounds of the number of tanks installed. $y_{t, p, s}^{s t}$ indicates

281 the installation of each tank $s$ on wellpad $p$ at time period $t$.

282 The total freshwater stored also depends on the number of freshwater impoundments

283 installed,

$284 \quad n_{t, p}^{i m}=n_{t-1, p}^{i m}+n_{t, p}^{i m, i n s} \quad \forall t \in T, p \in P$

$285 \quad N^{i m, L O} \cdot y_{t, p}^{i m} \leq n_{t, p}^{i m, i n s} \leq N^{i m, U P} \cdot y_{t, p}^{i m} \quad \forall t \in T, p \in P$

286

$s t_{t, p, s}+\theta_{t, p, s} \leq C S T_{s} \cdot n_{t, p, s}+V^{i m p} \cdot n_{t, p}^{i m} \quad \forall t \in T, p \in P, s \in\{f w t\}$

287 where $V^{i m p}$ is the capacity of an impoundment.

288 Water Demand

289 The amount of water required per wellpad $\left(f_{t, p}^{d e m}\right)$ can be supplied by a mixture of fresh

$290\left(f_{t, p}^{f r e}\right)$ or impaired water $\left(f_{t, p}^{i m p}\right)$,

$291 \quad f_{t, p}^{\text {dem }}=f_{t, p}^{\text {fresh }}+f_{t, p}^{i m p} \quad \forall t \in T, p \in P$

292 The fracturing water $\left(f_{t, p, w}^{d e m}\right)$ required in each well is given by constraint (17),

$293 \quad f_{t, p}^{d e m}=\sum_{w \in R P W_{p}} f_{t, p, w}^{d e m} \quad \forall t \in T, p \in P$

294 The following constraint indicates that the water available at each well, when the well is

295 fractured must be greater or equal than the water demand of each well $\left(W D_{w}\right)$, 
A. Carrero-Parreño et al.

296

$$
f_{t, p, w}^{d e m} \geq W D_{w} \cdot \sum_{c \in C} y_{t, p, w, c}^{h f} \quad \forall t \in T, w \in R P W_{p}, p \in P
$$

297 Onsite treatment

298 Mass balance around onsite pretreatment technology is described in Eq.(19). The total

299 inlet wastewater that enters in the pretreatment in wellpad $\mathrm{p}$ in time period $\mathrm{t}$ is equal to

300 the outlet pretreated stream plus the sludge stream.

301

$$
f_{t, p}^{\text {pre,in }}=f_{t, p}^{\text {pre,out }}+f_{t, p}^{\text {on,slud }} \quad \forall t \in T, p \in P
$$

302 The relation between the inlet and outlet mass flowrate is modeled by using the recovery

303 factor $\left(\alpha^{\text {pre }}\right)$,

$304 \quad f_{t, p}^{\text {pre,out }}=\alpha^{\text {pre }} \cdot f_{t, p}^{\text {pre,in }} \quad \forall t \in T, p \in P$

305 After pretreatment, the water can be used as a fracturing fluid $\left(f_{t, p}^{i m p}\right)$ or/and can be sent

306 to a desalination unit $\left(f_{t, p}^{o n, i n}\right)$,

$f_{t, p}^{\text {pre,out }}=f_{t, p}^{\text {imp }}+f_{t, p}^{\text {on,in }} \quad \forall t \in T, p \in P$

308 The total and salt balances around the onsite desalination treatment are given by Eqs. (22-

309 23). In order to achieve the outlet stream close to ZLD conditions, the outlet brine salinity

$310\left(C^{z l d}\right)$ is fixed to $300 \mathrm{~g} \cdot \mathrm{kg}^{-1}$ (close to salt saturation condition of $\sim 350 \mathrm{~g} \cdot \mathrm{kg}^{-1}$ ).

$311 f_{t, p}^{\text {on,out }}+f_{t, p}^{\text {on, brine }}=f_{t, p}^{\text {on, in }} \quad \forall t \in T, p \in P$

312

$f_{t, p}^{\text {on, brine }} \cdot C^{z l d}=f_{t, p}^{o n, i n} \cdot c_{t, p} \quad \forall t \in T, p \in P$

313 Two options have been considered for TDS reduction such as MSMD and MEE-MVR.

314 The onsite desalination treatment is also leased. Hence, onsite treatment balance is

315 described in the following equations,

$316 \quad n_{t, p, n}^{o n}=n_{t-1, p, n}^{o n}+n_{t, p, n}^{o n, i n s}-n_{t, p, n}^{o n, u n i n s} \quad \forall t \in T, p \in P, n \in N$ 
A. Carrero-Parreño et al.

317 where $n_{t, p, n}^{o n}$ is the total number of onsite treatment leased in time period $t$ on wellpad $p$

318 using a desalination technology $n, n_{t, p, s}^{o n, i n s}$ and $n_{t, p, s}^{o n, u n i n s}$ represent the number of installed

319 or uninstalled onsite treatment in a specific time period.

320 The number of onsite treatment leased depends on the total number of portable treatments

321 available $\left(N_{n}^{\text {on,UP }}\right)$.

322

$N_{n}^{o n, L O} \cdot y_{t, p, n}^{o n} \leq n_{t, p, n}^{o n, i n s} \leq N_{n}^{o n, U P} \cdot y_{t, p, n}^{o n} \quad \forall t \in T, p \in P, n \in N$

323 Eq (26) represents the mass balance through the desalination unit,

$f_{t, p}^{o n, i n}=\sum_{n \in N} f_{t, p, n}^{o n, i n} \quad \forall t \in T, p \in P$

325 The selection of the treatment unit in each time period is represented by Eq. (27). If an onsite desalination unit $\mathrm{n}$ is selected in time period $t$ on wellpad $\mathrm{p}$, the integer variable

$327 n_{t, p, n}^{o n}$ is equal to the number of tanks needed in time period $t$ on wellpad $p$. The inlet

328 flowrate is bounded for the maximum and minimum capacity of each treatment unit

329 multiply by the total number of tanks leased. On the contrary, if the onsite treatment $n$ is

330 not needed in time period $t$ on wellpad $p$, the integer variable $n_{t, p, n}^{o n}$ takes the value of

331 zero, and consequently, the inlet flowrate is also zero.

$$
F_{n}^{o n, L O} \cdot n_{t, p, n}^{o n, i n s} \leq f_{t, p, n}^{o n, i n} \leq F_{n}^{o n, U P} \cdot n_{t, p, n}^{\text {on,ins }} \quad \forall t \in T, p \in P, n \in N
$$

333 The flow directions for the desalinated water are given by Eq.(28),

$$
f_{t, p}^{o n, o u t}=f_{t, p}^{o n, f w t}+f_{t, p}^{o n, d e s}+\sum_{p p \in P} f_{t, p, p p}^{p a d, f w t} \quad \forall t \in T, p \in P
$$

335 where $f_{t, p}^{o n, f w t}$ is the desalinated water sent to freshwater tank, $f_{t, p}^{o n, d e s}$ is the water

336 discharged on the surface and $f_{t, p, p p}^{p a d, f w t}$ is the desalinated water used as a fracturing fluid 337 in the same or other wellpad. 
A. Carrero-Parreño et al.

339

\section{Centralized water treatment}

340 In this section, mass balances are performed in the CWT facility. Eq. (29) shows the

341 relationship between the inlet and outlet streams, and Eq. (30) constraints the inlet

342 flowrate of CWT $k$ with the maximum flowrate allowed.

$343 \quad f_{t, k}^{c w t, \text { out }}=\alpha_{k}^{r e c} \cdot \sum_{p \in P} f_{t, p, k}^{c w t, i n} \quad \forall t \in T, k \in K$

$344 \sum_{p \in P} f_{t, p, k}^{c w t, i n} \leq F_{k}^{c w t, U P} \quad \forall t \in T, k \in K$

345 The freshwater mass balance at the end of CWT k is given by Eq.(31),

$346 \quad f_{t, k}^{c w t, \text { out }}=\sum_{p \in P} f_{t, p, k}^{c w t, f w t}+f_{t, k}^{c w t, d e s} \quad \forall t \in T, k \in K$

\section{Sustainability profit - Objective function}

348 The objective function, which is to be maximized, comprises the economic-profit

349 ( $\left.p^{\text {Economic }}\right)$, eco-cost $\left(\mathrm{c}^{\text {Eco }}\right)$ and social-profit $\left(p^{\text {Social }}\right)$.

$350 \quad \max : s p=p^{\text {Economic }}-c^{\text {Eco }}+p^{\text {Social }}$

351 Economic profit consists of revenues from natural gas minus the sum of the following

352 expenses: drilling and production cost, wastewater disposal cost, storage tank cost,

353 freshwater cost, friction reducer cost, wastewater and freshwater transport cost and onsite

354 and offsite treatment cost.

355

$p^{\text {Economic }}=r^{\text {gas }}-\left(e^{\text {drill }}+e^{\text {dis }}+e^{\text {sto }}+e^{\text {source }}+e^{f r}+e^{\text {trans }}+e^{\text {ondes }}+e^{\text {cut }}+e^{\text {crew }}\right)$

356 The revenues of shale gas sales can be represented by Eq. (34),

$357 \quad r^{g a s}=\sum_{t \in T} \sum_{p \in P} \sum_{w \in R P W_{p}} \sum_{t t=0}^{t t \leq t-1} F_{t-t t, p, w}^{g a s} \cdot y_{t t+1, p, w}^{f b} \cdot \alpha_{t}^{g a s}$

358 where $F_{t, p, w}^{g a s}$ is the gas production and $\alpha_{t}^{g a s}$ is the gas price forecast in time period $t$.

359 Drilling, completion and production cost are defined by Eq. (35), 
A. Carrero-Parreño et al.

$e^{d r i l l}=\sum_{t \in T} \sum_{p \in P} \sum_{w \in R P W_{p}} \sum_{c \in C} \alpha^{d r i l l} \cdot y_{t, p, w, c}^{h f}+\sum_{t \in T} \sum_{p \in P} \sum_{w \in R P W_{p}} \alpha^{p r o d} \cdot f_{t, p, w}^{g a s}$

361 Disposal expenses only include the disposal costs $\alpha_{d}^{d i s}$ which depend on the place where

362 the class II disposal well is located,

$363 \quad e^{d i s}=\sum_{t \in T} \sum_{p \in P} \sum_{d \in D} \alpha_{d}^{d i s} \cdot f_{t, p, d}^{d i s}$

364 Fracturing, impaired water and freshwater tanks are typically leased, the cost is made up

365 of leasing cost $\left(\alpha_{s}^{\text {sto }}\right)$ and mobilize, demobilize and cleaning $\operatorname{cost}\left(\beta_{s}^{\text {sto }}\right)$ as follows,

$$
e^{s t o}=\sum_{t \in T} \sum_{p \in P} \sum_{s \in S}\left(\alpha_{s}^{s t o} \cdot n_{t, p, s}+\beta_{s}^{s t o} \cdot n_{t, p, s}^{i n s}\right)+\sum_{t \in T} \sum_{p \in P} \alpha^{i m} \cdot n_{t, p}^{i m, i n s} \cdot V^{i m}
$$

367 Where $\alpha^{i m}$ represents the cost of the impoundments construction. The freshwater cost

368 includes the withdrawal cost from the diverse sources $f$,

$$
e^{\text {source }}=\sum_{t \in T} \sum_{p \in P} \sum_{f \in F} \alpha_{f}^{\text {source }} \cdot f_{t, p, f}^{\text {source }}
$$

370 The friction reducers costs are given by Eq.(39). They depend on the TDS concentration

371 and the flowrate used for hydraulic fracturing,

$$
e^{f r}=\sum_{t \in T} \sum_{p \in P}\left(\alpha^{f r} \cdot c_{t, p}+\beta^{f r}\right) \cdot f_{t, p}^{i m p}
$$

373 Transportation expenses by truck involve the sum of the following transfers: (1) from

374 wellpad $p$ to disposal location $d$, (2) from freshwater source $f$ to wellpad $p$, (3) from 375 wellpad $p$ to offsite treatment $k$, and (4) from wellpad $p$ to wellpad $p p$.

$$
e^{\text {truck }}=\alpha^{\text {truck }} \cdot \sum_{t \in T} \sum_{p \in P}\left(\begin{array}{l}
\sum_{d \in D} f_{t, p, d}^{\text {dis }} \cdot D_{p, d}^{\text {pad }- \text { dis }}+\sum_{f \in F} f_{t, p, f}^{\text {source }} \cdot D_{f, p}^{\text {pad-source }} \\
+\sum_{k \in K}\left(f_{t, k}^{c w t, i n}+f_{t, p, k}^{c w t, f w t}\right) \cdot D_{p, k}^{\text {pad }-c w t} \\
+\sum_{p p \in P}\left(f_{t, p, p p}^{\text {pad }}+f_{t, p, p p}^{p a d, i m p}\right) \cdot D_{p, p p}^{\text {pad }- \text { pad }}
\end{array}\right)
$$

377 where $D_{p, d}^{\text {pad-d }}, D_{p, f}^{\text {pad-sourc }}, D_{p, k}^{p a} \quad$ and $D_{p, p p}^{\text {pad-pad }}$ are the distances from wellpad $p$

378 to disposal site $d$, source $f$, CWT facility and wellpad $p p$. 
A. Carrero-Parreño et al.

379 Pretreatment expenses depend on the wastewater destination. Obviously, requirements to

380 desalinate the water in thermal treatment or membrane treatments are more restrictive

381 than the requirements to reuse it in fracturing operations. As described in Eq. (41), $\alpha^{\text {reuse }}$

382 represents the pretreatment cost aiming its reuse, and $\alpha^{\text {treat }}$ the pretreatment cost aiming

383 to remove TDS by desalination technologies. Onsite TDS removal unit cost includes

384 desalination cost $\left(\alpha_{n}^{o n}\right)$, mobilize, desmobilize and cleaning cost $\left(\beta_{n}^{o n}\right)$ and leasing cost

$385\left(\alpha_{n}^{\text {on }}\right)$.

$386 e^{\text {ondes }}=\sum_{t \in T} \sum_{p \in P}\left[\alpha^{\text {reuse }} \cdot f_{t, p}^{\text {imp }}+\alpha^{\text {treat }} \cdot f_{t, p}^{\text {on,in }}+\sum_{n \in N}\left(\alpha_{n}^{o n} \cdot n_{t, p, n}^{o n}+\beta_{n}^{o n} \cdot n_{t, p, n}^{o n, i n s t}\right)\right]$

387 The CWT cost is given by Eq. (42) and it depends on the cost that the treatment plant

388 imposes for treating the flowback water from shale gas operations $\left(\alpha_{k}^{c w t}\right)$.

389

$e^{c w t}=\sum_{t \in T} \sum_{p \in P} \sum_{k \in K} \alpha_{k}^{c w t} \cdot f_{t, p, k}^{c w t, i n}$

390 The cost of moving crews and rigs depends if the candidate well is going to be fractured

391 in the same or other wellpad. With that purpose, the binary variable $y_{t, p, c}^{c r e w}$ is equal to one

392 if at least one well is drilled in wellpad $p$ in time period $t$ by crew $c$,

$393 \quad y_{t, p, c}^{\text {crew }} \geq \sum_{w \in R P W_{p}} y_{t, p, w, c}^{h f} \quad \forall t \in T, p \in P, c \in C$

$394 \sum_{p \in P} y_{t, p, c}^{\text {crew }} \leq 1 \quad \forall t \in T, c \in C$

395 Clearly, if the fracturing crew $c$ in time period $t$ is on the same wellpad in time period t-

3961 , the fracturing expenses are equal to zero.

397

$e^{\text {crew }}=\sum_{t \in T} \sum_{p \in P} \sum_{c \in C} \alpha^{\text {crew }} \cdot\left(y_{t, p, c}^{c r e w}-y_{t-1, p, c}^{c r e w}\right)$

398 Eco-cost is a robust indicator from cradle-to-cradle LCA calculations in the circular economy that includes eco-costs of human health, ecosystems, resource depletion and

400 global warming. The terms are calculated by using eco-cost coefficients. ${ }^{28}$ In our problem, 
401 the eco-cost term includes natural gas extraction, freshwater withdrawal, desalination,

402 disposal and transportation. The eco-cost to be minimized is defined by Eq. (46),

$403 \quad c^{E c o}=\sum_{r \in R} \mu_{r} \cdot q_{r}+\sum_{g \in G} \mu_{g} \cdot q_{g}+\sum_{r \in R} \mu_{r}^{T} \cdot D \cdot q_{r}+\sum_{g \in G} \mu_{g}^{T} \cdot D \cdot q_{g}$

404 where $\mathrm{r}$ and $\mathrm{g}$ are indices for raw materials and products, respectively. $\mu$ represents eco-

405 cost of raw materials and products and $\mu^{T}$ is the eco-cost of transportation. All coefficients

406 are proportional to mass flows $(q)$.

407 Social profit, displayed by Eq. (47), comprises social security contributions paid for the 408 employees to fracture a well (SS), plus the social transfer by hiring people (SU), minus

409 social cost (SC). ${ }^{24} \mathrm{We}$ only contemplate the number of jobs on a fracturing crew and the

410 working hours per employee needed to fracture a specific well. Once the well is 411 completed, the number of jobs generated by maintenance team or truck drivers are not

412 contemplated.

$p^{\text {Social }}=S S+S U+S C=$

$413 \sum_{t \in T} \sum_{p \in P} \sum_{w \in R P W_{p}} \sum_{c \in C} y_{t, p, w, c}^{h f} \cdot\left[\mathrm{N}^{j o b s} \cdot\left(S^{\text {Gross }}-S^{N e t}\right)+\mathrm{N}^{j o b s} \cdot C^{U N E, \text { State }}-\mathrm{N}^{\text {jobs }}\left(C^{E M P, \text { State }}+C^{\text {Company }}\right)\right] \cdot \tau_{w}^{h f}$

414 where $N^{\text {jobs }}$ is the number of new jobs needed to fracture a well, $S^{\text {gross }}$ and $S^{\text {net }}$ are the

415 average gross and net salaries paid for each employee, $C^{U N E, \text { State }}$ is the average social

416 transfer for unemployed people, $C^{E M P, \text { State }}$ is the state social transfer (i.e child allowance,

417 state scholarship, health insurance) and $C^{\text {company }}$ is company's social charge (i.e team

418 building events, excursions, cultural activities).

\section{SOLUTION STRATEGY}

421 The optimization problem is modeled using total flows and salt composition as variables.

422 This proposed MINLP model -Eqs. (1)-(47)- involves bilinear terms in the salt water mass 423 balances: Eqs. (7), (9), (23) and (39). These terms are the source of the non-convexity in 
A. Carrero-Parreño et al.

424 the model. An advantage of using this representation is that the bounds of the variables

425 present in the non-convex bilinear terms can be easily determined. If local solvers are 426 selected to solve the MINLP problem, we may converge to a local solution. Global optimization solvers can in principle be used but may not reach a solution for a large scale non-convex MINLP problems in a reasonable period of time. Thus, we propose the following decomposition strategy in order to achieve a trade-off between the solution 430 quality vs time.

- The original MINLP is relaxed using under and over estimators of the bilinear terms, McCormick convex envelope ${ }^{29}$, which leads to an MILP. To this aim, the bilinear terms in constraints (7), (9), (23) and (39) are replaced by the following equations. The solution of this MINLP yields an upper bound (UB) to the original MINLP.

436 $\left.\begin{array}{l}s \geq c \cdot F^{L O}+C^{L O} \cdot f-C^{L O} \cdot F^{L O} \\ s \geq C^{U P} \cdot f+c \cdot F^{U P}-C^{U P} \cdot F^{U P}\end{array}\right\}$ Underestimators $s \leq c \cdot F^{U P}+C^{L O} \cdot f-C^{L O} \cdot F^{U P}$ $\left.s \leq C^{U P} \cdot f+c \cdot F^{L O}-C^{U P} \cdot F^{L O}\right\}$ Overstimators where $\mathrm{s}$ is the corresponding bilinear term and flow and $C^{L O}, F^{L O}, C^{U P}$ and $F^{U P}$ are the lower and upper bound of salt concentrations and flows.

- The binary variables obtained in the previous MILP, that determine the fracture schedule $\left(y_{t, p, w, c}^{h f}\right)$, are fixed into the original MINLP, resulting in a smaller MINLP involving the binary variables $y_{t, p, s}^{s t}$ and $y_{t, p, n}^{o n}$.

442 The mathematical model is implemented in GAMS 25.0.1..$^{30}$ The relaxed MILP problem 443 is solved with Gurobi 7.5. $2^{31}$ and the MINLP problem with DICOPT $2^{32}$ using CONOPT $4444^{33}$ to solve the NLP sub-problems. DICOPT cannot guarantee a global solution, however, 
A. Carrero-Parreño et al.

445 we calculate the optimality gap, defined by Eq. (49), to obtain the deviation of this

446 solution with respect to the global optimum,

$447 \quad g a p=\frac{U B-L B}{U B}$

448 The relaxed MILP problem has 3,273 binary variables, 21,373 continuous variables and

44920,600 constraints. In the reduced non-convex MINLP, the binary variables decrease to

4502,337 by using the solution of the relaxed MILP problem that provides the fracturing

451 schedule for the non-convex MINLP. The reduced non-convex MINLP has 14,607

452 continuous variables and 9,361 constraints. The model has been solved on a computer

453 with a $3 \mathrm{GHz}$ Intel Core Dual Processor and 4 GB RAM running Windows 10.

454

455

5. CASE STUDIES

456

The case studies shown in Table 1 based on Marcellus Play illustrate the capabilities of

the proposed optimization model. They are composed by 20 wells grouped in 3 wellpads, one year discretized at one week per time period, three Class II disposal wells, four interruptible sources of freshwater, two CWT plants and one fracturing crew. The difference between interruptible sources, disposal wells and CWT plants lies in the geographical location. Data of the problem -cost coefficients and model parameters- are

462 given in Supporting Information (Tables S.1-S.4). Gross and net salaries paid for each 463 employee are obtained from the Bureau of Labor Statistics. ${ }^{34}$ Our goal is to determine the 464 optimal planning solution from well drilling and construction to the end of flowback water generation. Therefore, we consider the natural gas production and wastewater generated in the first twelve weeks, which is the critical period for shale gas water management. In

467 this phase, the coordination among different contractors is crucial since the water is 468 recovered in a short time period. In this work, we assume that $50 \%$ of the water used to 469 fracture a well (water demand per well), which ranges from 4,800 to $18,600 \mathrm{~m}^{3}$, is 
A. Carrero-Parreño et al.

470 recovered as flowback water. Additionally, we consider that the TDS concentration

471 depends on each well and increases with time ranging from 3,000 to 200,000 ppm.

Table 1. Case studies description

\section{Case study Description}

Case 1 All water management options are allowed: reuse the flowback water with a ligth treatment, desalinate the water in onsite treatment or CWT facility, reuse the desalinated water as a fracturing fluid and disposal in class II disposal wells.

Case 2 Disposal in class II disposal wells is the only water management option allowed.

Case 3 Wastewater can be sent to onsite desalination treatment or CWT facility.

Case 4 The highest estimated cost for friction reducers is assumed for the whole range of salinity concentrations. Thus Eq. (39) is replaced by:

$$
E^{f r}=\sum_{t \in T} \sum_{p \in P} \gamma^{f r} \cdot f_{t, p}^{i m p}
$$

Case 5 All water management options, as in Case 1, are permitted. However, return to pad-operations is not allowed and wells are fractured in order; well 2 cannot be fractured before well 1 . Accordingly, the following constraint is added:

$$
\sum_{t \in T} t \cdot y_{t, p, w, c}^{h f} \leq \sum_{t \in T} t \cdot y_{t, p, w w, c}^{h f} \quad w<w w, \forall w \in R P W_{p}, p \in P
$$


a)

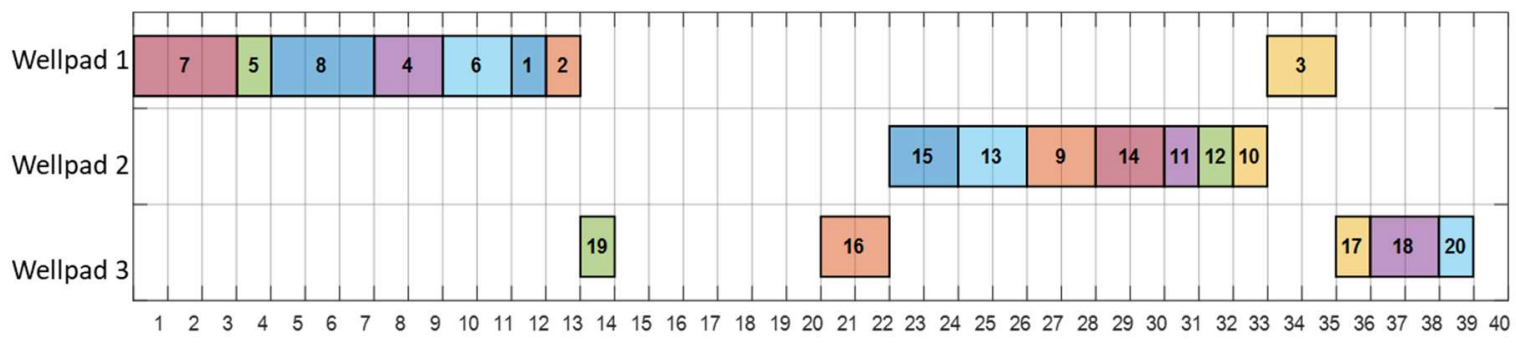

b)

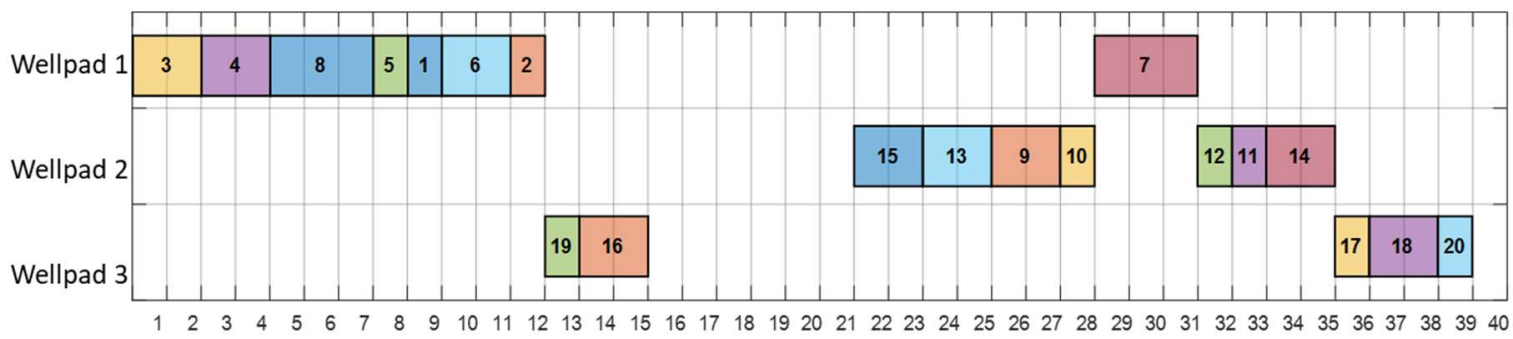

c)

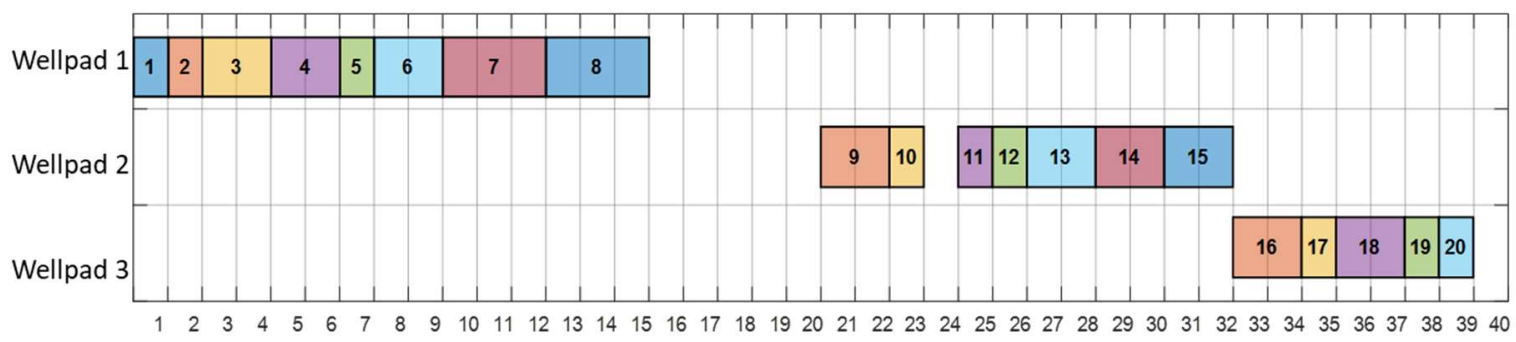

Time(week)

Figure 2. Fracturing schedule obtained after economic, social and environmental optimization of the shale gas planning model: (a) Case 1; (b) Cases 2,3 and 4; (c) Case 5.

For each case study, the optimal fracturing schedule and the sustainability profit, which is a weighted sum of three objectives eco-cost, social-profit and economic-profit, are shown in Figure 2 and Table 2, respectively. It should be mentioned that all wells are

481 fractured before time period forty starts to allow that all the flowback water is considered by the model. Figure 2 highlights that the same fracturing schedule is obtained for Cases 2, $3 \& 4$, where the economic-profit, driven by the maximization of shale gas revenues, controls the sustainability profit. In Case 1, the fracturing schedule maximizes the total water reused for fracturing purposes, reducing the eco-cost to $\$ 17,490 \mathrm{k}$ and increasing the economic-profit (due to cost reduction is greater than revenues decrease) to $\$ 16,909 \mathrm{k}$, 
A. Carrero-Parreño et al.

487 which is the lowest of the five cases (see Table 2). Therefore, in this case, the water 488 management selected is direct reuse to fracture other wells, and once all wells been 489 fractured, the wastewater is desalinated in onsite treatments.

490 Additionally, although the cost of moving a fracturing crew from one wellpad to another 491 is significant, the optimal facturing schedule (Figure 2) reveals that raising the number of 492 these movements increase the sustainability profit (Table 2). For example, in the optimal 493 fracturing schedule for Case 1, fracturing crew moves from wellpad 1 to wellpad 3, before 494 fracturing all wells belonging wellpad 1, and again, before wellpad 2 completion, 495 fracturing crew travel from wellpad 3 to 2 (in total there 4 transitons). The underlying 496 logic for this unexpected crew's shift schedule are twofold: the shale gas price forecast 497 and the well gas production.

Table 2. Contribution of each objective (eco cost, social profit and economic profit) to the weighted average objective (sustainability profit, $\mathrm{k} \$$ ).

\begin{tabular}{llllll}
\hline & Case 1 & Case 2 & Case 3 & Case 4 & Case 5 \\
& & & & & \\
\hline Sustainability profit & 840 & $-16,325$ & -57 & 709 & $-1,629$ \\
Eco-cost & 17,490 & 22,584 & 17,599 & 17,502 & 17,495 \\
Social-profit & 1,421 & 1,421 & 1,421 & 1,421 & 1,421 \\
Economic-profit & 16,909 & 4,838 & 16,120 & 16,789 & 14.444 \\
Gap MILP-MINLP (\%) & 0.86 & 1.99 & 4.21 & 0.36 & 0.86 \\
\hline
\end{tabular}

500

501 Reusing the flowback water for subsequent fracturing requires to add costly friction 502 reducers. However, we can realize comparing the results obtained of Case $2 \& 3$ vs Case 5031 (see Table 3) that reusing the wastewater yields large savings in freshwater 
A. Carrero-Parreño et al.

504 transportation cost, and treatment and withdrawal cost of the impaired water. It is

505 important to highlight that although $90,580 \mathrm{~m}^{3}$ of impaired water is reused, freshwater is

506 still necessary $\left(132,720 \mathrm{~m}^{3}\right)$ as the flowback only represents $50 \%$ of the water injected

507 into the well. Figure 3 shows the freshwater and impaired water used for each case study.

508
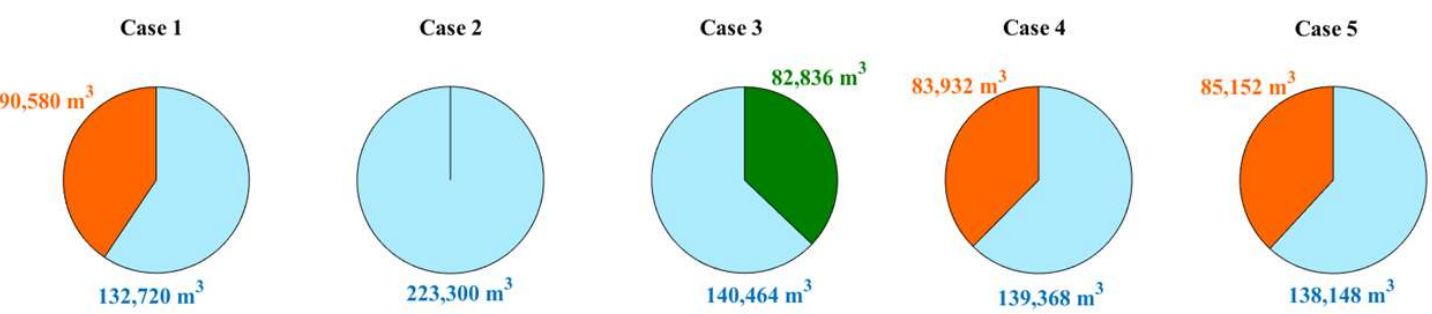

509

$\square$ Impaired Water $\square$ Freshwater $\square$ Desalinated water

Figure 3. Total impaired water and freshwater used for all case studies.

In Case 4, where the friction reducers cost assumed is the highest, the impaired water used as fracturing fluid decreases by $7.3 \%$ with respect Case 1 . This fact highlights the influence of the cost of friction reducers in the planning decisions. In addition, the suitanibility profit for Case $4(\$ 709 \mathrm{k})$ decreases by $13 \%$ with respect Case 1 . However,

516 the former is a viable solution (i.e., a positive sustanbility profit) among economic,

517 environmental and social criteria. As Case 4 was designed at the worst case (i.e., the 518 highest friction reducer cost), an additional benefit of its solution is that exhibits a good

519 performance even if the concentration of TDS would increase due to the use of impaired 520 water over the time, which implies a higher fiction reducer cost.

521 In case studies $2,3 \& 5$, a compromise solution is not found. Therefore, the sustainability 522 profit is negative, and no wells should be fractured. Nevertheless, in these cases, we 523 enforce that all wells must be fractured at the end of the time period in order to compare the results obtained with case studies $1 \& 4$. 
525 In Case 2, where the only water management option considered is water disposal, is the

526 worst scenario studied, being the sustainability profit equal to $-\$ 16,325 \mathrm{k}$. Both eco and 527 economic costs are too high compared with other case studies. Hence, the results highlight

528 that injecting wastewater into Class II disposal wells should be excluded for wells based 529 on Marcellus play. When only desalination is allowed (Case 3), both economic-cost and 530 eco-cost decrease significantly compared with Case 2. However, sustainability profit still 531 remains negative equal to - $\$ 57 \mathrm{k}$. In this case, part of desalinated water is reused to 532 fracture other wells. This allows important economic and environmental savings in 533 transportation and water withdrawal. Finally, it is interesting to mention that in Case 5, 534 where the fracturing schedule is restricted to be sequential, is the second worst scenario. 535 Although the wastewater reused $\left(85,152 \mathrm{~m}^{3}\right)$ is close to the impaired water of the first 536 scenario $\left(90,580 \mathrm{~m}^{3}\right)$, the revenue obtained from natural gas decreases $9 \%$ compare with 537 the revenue obtained from Case 1. This result clearly shows the dependency of the 538 fracturing schedule on the price and production forecast of natural gas.

539 It should be noted that in all cases, water-related costs range from 5 to $13 \%$ of the revenue 540 of shale gas production. Figure 4 displays the percentage contribution of each water541 related cost (additives, freshwater withdrawal, disposal, storage, transportation, and 542 desalination) of the total water cost and Table 3 details economic-cost and eco-cost of 543 each case study. Regarding economic criterion, the cost of drilling and production for 544 Cases 1, 3, $4 \& 5$ represent the highest contribution of the total cost, and in Case 2, the 545 disposal cost is the highest one $(\$ 10,165 \mathrm{k})$. Regarding the environmental criterion, the 546 eco-cost of natural gas production is equal to $\$ 17,375 \mathrm{k}$, which is significantly higher than 547 the others eco-cost calculated (see Table 3). 
A. Carrero-Parreño et al. case studies $(\mathbf{k} \$)$.

\begin{tabular}{|c|c|c|c|c|c|c|}
\hline & & Case 1 & Case 2 & Case 3 & Case 4 & Case 5 \\
\hline \multirow{9}{*}{ 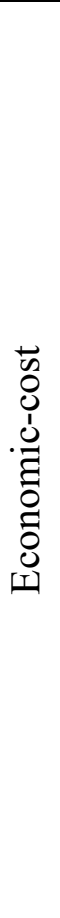 } & Cost moving crew & 415 & 498 & 498 & 498 & 249 \\
\hline & $\begin{array}{l}\text { Cost drilling and } \\
\text { production }\end{array}$ & 9,523 & 9,523 & 9,523 & 9,523 & 9,523 \\
\hline & $\begin{array}{l}\text { Cost friction } \\
\text { reducers }\end{array}$ & 167 & 0 & 0 & 252 & 157 \\
\hline & $\begin{array}{l}\text { Cost freshwater } \\
\text { acquisition }\end{array}$ & 262 & 472 & 291 & 271 & 269 \\
\hline & Cost disposal & 0 & 10,165 & 0 & 0 & 0 \\
\hline & Cost storage & 370 & 457 & 666 & 381 & 289 \\
\hline & Cost transport & 833 & 2,903 & 811 & 857 & 784 \\
\hline & $\begin{array}{l}\text { Cost onsite- } \\
\text { treatment }\end{array}$ & 243 & 0 & 900 & 293 & 280 \\
\hline & Cost CWT & 0 & 0 & 47 & 0 & 0 \\
\hline \multirow{5}{*}{$\begin{array}{l}\ddot{n} \\
0 \\
0 \\
\vdots \\
0 \\
1 \\
1\end{array}$} & $\begin{array}{l}\text { Eco-cost freshwater } \\
\text { acquisition }\end{array}$ & 28 & 50 & 31 & 29 & 30 \\
\hline & Eco-cost disposal & 0 & 4,931 & 0 & 0 & 0 \\
\hline & $\begin{array}{l}\text { Eco-cost } \\
\text { desalination }\end{array}$ & 22 & 0 & 129 & 30 & 29 \\
\hline & $\begin{array}{l}\text { Eco-cost natural } \\
\text { gas production }\end{array}$ & 17,375 & 17,375 & 17,375 & 17,375 & 17,375 \\
\hline & $\begin{array}{l}\text { Eco-cost } \\
\text { transportation }\end{array}$ & 66 & 228 & 64 & 67 & 62 \\
\hline
\end{tabular}

551

552 Transportation cost decreases reusing the wastewater to fracture other wells (see Table 3

553 Cases $1,4 \& 5$ vs Cases $2 \& 3$ ). However, it still represents a high contribution to the 554 final economic and environmental water-related cost (see Figure 4). Except from Case 2, 555 which disposal constitute the highest eco and economic percentage, transportation 
A. Carrero-Parreño et al.

represents around $45 \%$ of the total water-related economic-cost, and around $80-60 \%$ of

557 the eco-cost.

558 Other authors include transportation of freshwater via pipelines to avoid impacts such as road damages, traffic accidents and $\mathrm{CO}_{2}$ emissions. ${ }^{13,16}$ Nevertheless, in this work, we

560 only consider truck hauling since it provides enough flexibility to guarantee freshwater

561 supply without the uncertainty of pipelines construction permits.

562
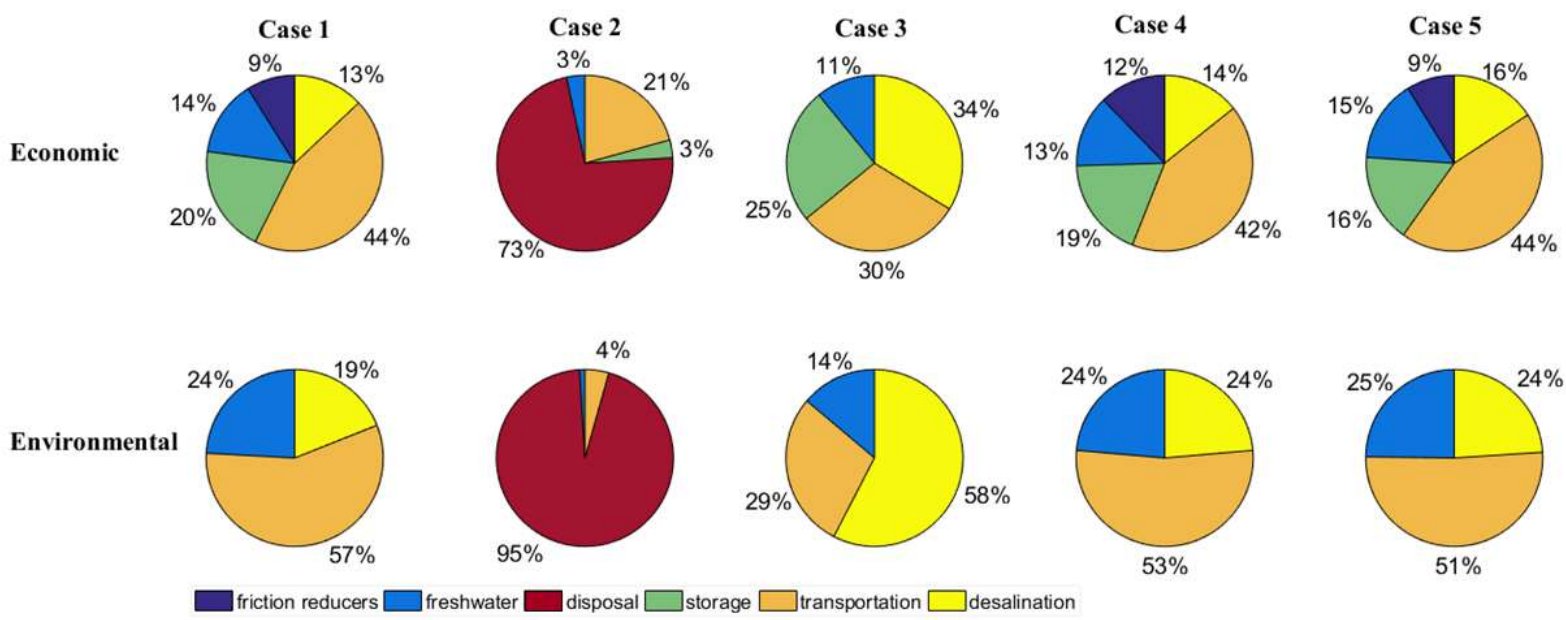

563

Figure 4. Comparison of all cases of the contribution percentage of each economic and environmental cost of the total water-related cost.

Despite the concern over the usage of freshwater for well fracturing, economic-cost and eco-cost of water withdrawal only represent around $15 \%$ of the total water-related cost.

However, it is important to take into consideration that freshwater withdrawal is an issue in water-scarce areas, where the water demand is high. In these areas, producers must

571 deal with higher water withdrawal cost, environmental impact and with the competition

572 to gain water withdrawal permits.

573 The results obtained also provides a realistic cost storage estimation. We rigorously 574 calculate the number of tanks leased in each time period considering installing, 
A. Carrero-Parreño et al.

575 uninstalling, clean out and leasing costs. Figure 5 displays, for Case 1, the number of

576 fracturing tanks and freshwater tanks leased over the time for each wellpad. Simplifying

577 the storage solution and considering that the maximum capacity needed is available from

578 the first to the last time period, as other authors have assumed ${ }^{13,18}$, the storage cost

579 increases by $53 \%$, changing the planning decisions. Note that once the storage tanks are

580 installed, it is more profitable to pay the leasing cost of the storage until all the wells

581 belonging to the wellpad $\mathrm{p}$ have been fractured than install and uninstall them over the

582 time. For example, see wellpad 3 in Figure 2 (a), where well 19 and 16 are fractured in

583 time period 13 and 20, and wells 17,18 and 20 in time period 35, 36 and 38 . That means

584 that freshwater tanks would not be required from time period 20 to 35 , however, they

585 remain installed.
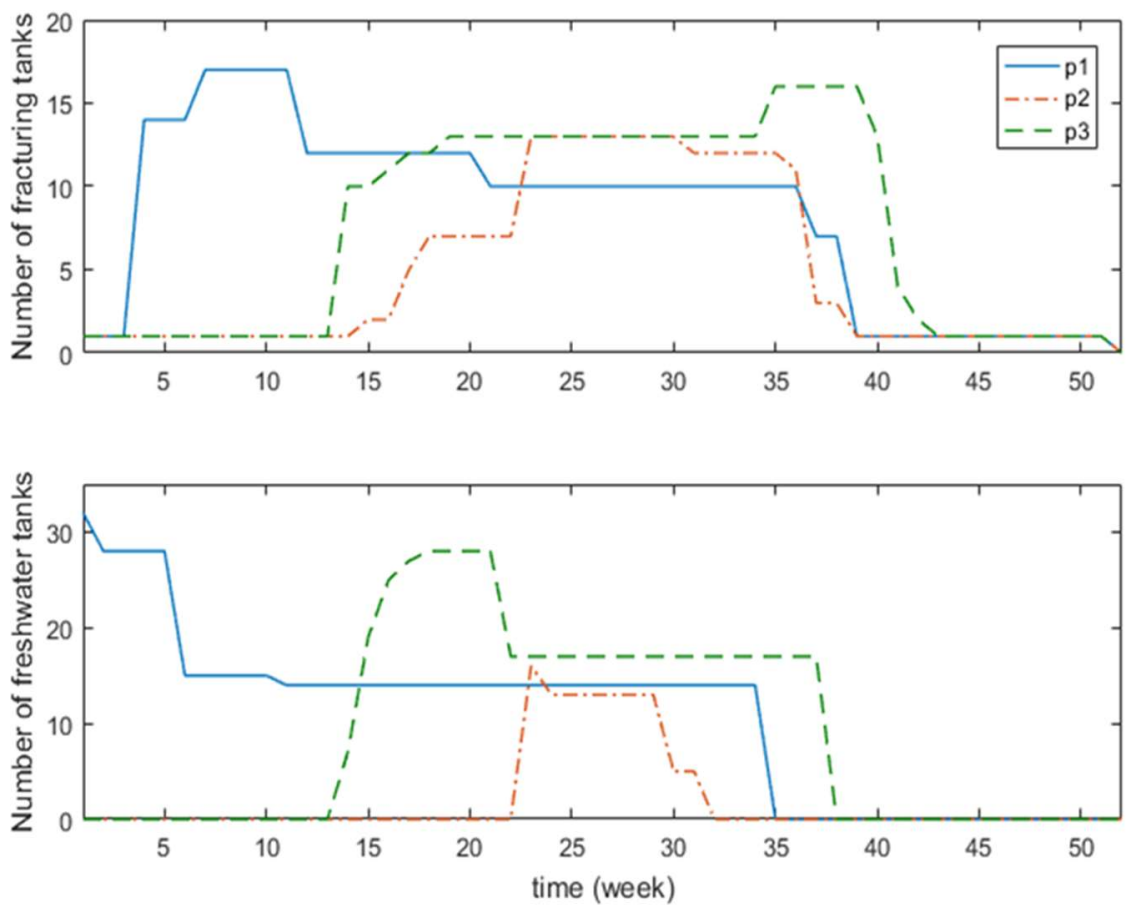

586

587 Figure 5. Number of fracturing tanks and freshwater tanks leased over the time for each wellpad in case study 1 . 
A. Carrero-Parreño et al.

\section{CONCLUSIONS}

590 An MINLP mathematical model has been proposed accounting for economic, 591 environmental and social objectives in shale gas production, considering the TDS 592 concentration of flowback and impaired water. The sustainability profit, a new weighted 593 sum objective expressed in monetary value, helps the decision-makers towards more 594 economic and sustainable decisions. The goal is to maximize this objective function to

595 find a compromise solution among the three pillars of sustainability: the economic-profit, 596 the eco-cost and the social-profit. The economic indicator includes revenue from natural

597 gas and cost related to drilling and production, storage, freshwater withdrawal, friction 598 reducer, transportation, disposal and treatment. The environmental indicator takes into 599 consideration cost of transportation, treatment, disposal, water withdrawal and shale gas 600 extraction. Finally, the social indicator includes social security contributions, social 601 effects due to the new jobs created and social cost.

602 This work also includes a study of the effect of friction reducers cost as a function of TDS 603 concentration to determine if reusing impaired water is a cost barrier. Additionally, the 604 rigorous calculation of storage solution permits operators to know the number of tanks 605 that should be leased in each time period, and hence, it provides a more realistic cost 606 storage estimation.

607 To solve the non-convex MINLP model effectively we use a decomposition technique.

608 First, the original problem is relaxed using McCormick convex envelopes obtaining a 609 relaxed MILP. Then, the fracturing schedule is fixed, and the reduced MINLP is solved. 610 The multi-objective problem is solved using the weighted sum method saving time

611 efforts. In this sense, there is no need to solve the large problem many times (a exponential 612 increase with the number of objectives), which is required to obtain a Pareto frontier in a 613 3-dimensional space. 
614 We apply our model to different case studies based on Marcellus Play. Different

615 assumptions are analyzed in each case study to gain a clear understanding of the nature

616 of the problem. The results reveal that reusing flowback water is compulsory to obtain a

617 compromise solution among the three pillars of sustainability: economic, environmental

618 and social criteria. Furthermore, the solution unveils that the level of TDS in reused water

619 is not an obstacle to use it as fracturing fluid in shale gas operations, although the

620 concentration increases over the time, and consequently the cost of the friction reducers.

621 Regarding the wastewater management alternatives, it has been also shown that onsite

622 desalination is the most cost-effective once water demand for fracturing new wells would

623 be less than the volume of water produced by active wells. Finally, it should be noted that

624 transportation is the highest water-related contribution to both economic and 625 environmental impacts.

626 It is worth mentioning that the results obtained provide realistic planning decisions for 627 the particular cases studies analyzed in this work. Nevertheless, shale gas water 628 management decisions are highly dependent on local regulations, geographical location 629 of the basin and local shale rock formation characteristics. For example, in Australia, 630 where shale gas reservoirs are in remote dry locations, disposal in evaporation ponds 631 might be economic and sustainable. Therefore, in this situation maybe there is no interest 632 in treat the water. In an eventual shale gas exploitation in Europe, the class II disposal is 633 likely to be forbidden and the sites will be close to populated areas. A policy of 634 wastewater direct reuse and desalination treatment will be mandatory in order to reduce 635 costs, environmental impacts and gain a favorable public perception (social impact). To 636 sum up, the mathematical model proposed would be a useful and robust tool, which would 637 help to take the best decisions under different circumstances. 
A. Carrero-Parreño et al.

\section{SUPPORTING INFORMATION}

640 Input data used in the case study: cost coefficients, model parameters, eco-cost and social 641 coefficients.

642

643 ACKNOWLEDGMENTS

644

This project has received funding from the European Union's Horizon 2020

645 Research and Innovation Program under grant agreement No. 640979 and from the 646 Spanish «Ministerio de Economía, Industria y Competitividad» CTQ2016-77968-C3-02647 P (FEDER, UE).

648

649 NOMENCLATURE

650 Parameters

$651 C_{t, p, w}^{\text {well }} \quad$ Concentration of flowback water forecast for well $\mathrm{w}$ on wellpad $\mathrm{p}$ in time period $\mathrm{t}, \mathrm{kg} \cdot \mathrm{kg}^{-1}$

653

$C^{c o n} \quad$ Outlet salinity for desalination treatments, $\mathrm{kg} \cdot \mathrm{kg}^{-1}$

$654 \quad \mathrm{CST}_{s} \quad$ Capacity of storage tank s, $\mathrm{m}^{3}$

$655 \quad D_{p, d}^{p a d-d i s} \quad$ Distance from wellpad $\mathrm{p}$ to disposal well $\mathrm{d}, \mathrm{km}$

$656 \quad D_{f, p}^{\text {pad-source }}$ Distance from source f to wellpad $\mathrm{p}, \mathrm{km}$

$657 \quad D_{p}^{p a d-o f f} \quad$ Distance from wellpad $\mathrm{p}$ to offsite-treatment, $\mathrm{km}$

$658 D_{p, p p}^{p a d-p a d} \quad$ Distance from wellpad $\mathrm{p}$ to wellpad $\mathrm{pp}, \mathrm{km}$

$659 F_{t, p, w}^{\text {nell }} \quad$ Flowback water forecast for well $\mathrm{w}$ on wellpad $\mathrm{p}$ in time period $\mathrm{t}, \mathrm{m}^{3} \cdot \mathrm{week}^{-1}$

$660 F_{n}^{o n, U P}, F_{n}^{o n, L O}$ Maximum and minimum onsite capacity for treatment $\mathrm{wt}, \mathrm{m}^{3} \cdot \mathrm{week}^{-1}$ 
$661 \quad F_{k}^{c w t, U P} \quad$ Maximum centralize water treatment capacity $\mathrm{k}, \mathrm{m}^{3} \cdot \mathrm{week}^{-1}$

$662 F_{t, p, w}^{\text {gas }} \quad$ Production gas flow forecast for well $\mathrm{w}$ on wellpad $\mathrm{p}$ in time period $\mathrm{t}$, $663 \mathrm{~m}^{3} \cdot$ week $^{-1}$

$664 \quad N_{s}^{U P}, N_{s}^{L O} \quad$ Upper and lower bound of tanks s installed

$665 N^{i m, U P}, N^{i m, L O}$ Upper and lower bound of impoundments installed

$666 N^{o n, U P}, N^{o n, L O}$ Upper and lower bound of onsite treatment leased

$667 \quad V^{i m} \quad$ Capacity of an impoundment, $\mathrm{m}^{3}$

$668 \quad W D_{w} \quad$ Water demand of well $\mathrm{w}, \mathrm{m}^{3}$

$669 \tau_{w} \quad$ Time to fracture well w, week

$670 \quad \alpha^{\text {pre }} \quad$ Pretreatment recovery factor

$671 \quad \alpha^{r e c} \quad$ Centralized water treatment recovery factor

$672 \quad \alpha^{\text {drill }} \quad$ Drilling and completion cost, $\$$

$673 \quad \alpha^{\text {prod }} \quad$ Shale gas production cost, $\$ \cdot \mathrm{m}^{-3}$

$674 \quad \alpha_{d}^{d i s} \quad$ Disposal coefficient cost coefficient for disposal $\mathrm{d}, \$ \cdot \mathrm{m}^{-3}$

$675 \quad \alpha_{s}^{\text {sto }} \quad$ Storage leasing cost coefficient for storage tank s, $\$ \cdot$ week $^{-1} \cdot \operatorname{tank}^{-1}$

$676 \quad \alpha^{i m} \quad$ Impoundment construction cost, $\$ \cdot \mathrm{m}^{-3}$

$677 \quad \alpha_{f}^{\text {source }} \quad$ Freshwater cost coefficient in freshwater source $\mathrm{f}, \$ \cdot \mathrm{m}^{-3}$

$678 \quad \alpha^{f r} \quad$ Friction reducer cost coefficient, $\$ \cdot \mathrm{m}^{-3}$

$679 \quad \alpha^{\text {truck }} \quad$ Trucking cost coefficient, $\$ \cdot \mathrm{km}^{-1} \cdot \mathrm{m}^{-3}$

$680 \quad \alpha^{\text {reuse }} \quad$ Pretreatment cost coefficient aiming its reuse, $\$ \cdot \mathrm{m}^{-3}$

$681 \quad \alpha^{\text {treat }} \quad$ Pretreatment cost coefficient aiming its desalination, $\$ \cdot \mathrm{m}^{-3}$

$682 \quad \alpha^{\text {crew }} \quad$ Cost of moving crews, $\$$ 
A. Carrero-Parreño et al.

683

$\alpha_{n}^{o n} \quad$ Onsite desalination cost coefficient for treatment $\mathrm{n}, \$ \cdot \mathrm{m}^{-3}$

$684 \quad \alpha_{k}^{c w t} \quad$ Cost coefficient of centralized water treatment $\mathrm{k}, \$ \cdot \mathrm{m}^{-3}$

$685 \quad \alpha_{t}^{\text {gas }} \quad$ Natural gas price forecast in time period $\mathrm{t}, \$ \cdot \mathrm{m}^{-3}$

$686 \quad \beta_{s}^{\text {sto }} \quad$ Mobilize, demobilize and cleaning cost coefficient for storage tank s, \$

$687 \quad \beta^{f r} \quad$ Friction reducer cost coefficient, $\$$

$688 \beta_{n}^{\text {on }} \quad$ Maintenance cost coefficient for onsite desalination treatment $\mathrm{n}, \$$

$689 \quad \gamma^{f r} \quad$ Overestimated cost of friction reducers, $\$ \cdot \mathrm{m}^{-3}$

690 Integer variables

$691 \quad n_{t, p, s} \quad$ Number of tank type s on wellpad $\mathrm{p}$ on time period $\mathrm{t}$

$692 \quad n_{t, p, s}^{i n s} \quad$ Number of tank type $\mathrm{s}$ installed on wellpad $\mathrm{p}$ on time period $\mathrm{t}$

$693 \quad n_{t, p, s}^{u n i s} \quad$ Number of tank type s uninstalled on wellpad $\mathrm{p}$ on time period $\mathrm{t}$

$694 \quad n_{t, p}^{i m} \quad$ Number of impoundments on wellpad $\mathrm{p}$ on time period $\mathrm{t}$

$695 \quad n_{t, p}^{i m, i n s} \quad$ Number of impoundments installed on wellpad $\mathrm{p}$ on time period $\mathrm{t}$

$696 \quad n_{t, p, n}^{o n} \quad$ Number of onsite treatment $\mathrm{n}$ on wellpad $\mathrm{p}$ on time period $\mathrm{t}$

$697 \quad n_{t, p, n}^{\text {on,ins }} \quad$ Number of onsite treatment $\mathrm{n}$ installed on wellpad $\mathrm{p}$ on time period $\mathrm{t}$

$698 \quad n_{t, p, n}^{\text {on,unis }} \quad$ Number of onsite treatment $\mathrm{n}$ uninstalled on wellpad $\mathrm{p}$ on time period $\mathrm{t}$

\section{Binary variables}

$700 y_{t, p, w, c}^{h f} \quad$ Indicates if well $\mathrm{w}$ on wellpad $\mathrm{p}$ is stimulating using fracturing crew $\mathrm{c}$ in

$701 \quad$ time period $\mathrm{t}$

$702 y_{t, p, s}^{s t} \quad$ Indicates if storage tank type s are installed on wellpad $\mathrm{p}$ in time period $\mathrm{t}$

$703 y_{t, p, n}^{o n} \quad$ Indicates if onsite treatment $\mathrm{n}$ is used on wellpad $\mathrm{p}$ in time period $\mathrm{t}$ 
A. Carrero-Parreño et al.

704

$y_{t, p, c}^{c r e w}$

705

706

707

$c_{t, p}^{p a d}$

708

709

710

711

712

$e^{d i s}$

$713 e^{\text {sto }}$

$714 e^{\text {source }}$

715

$e^{f r}$

716

$e^{\text {trans }}$

$717 e^{\text {ondes }}$

$718 e^{c w t}$

$719 e^{d r i l l}$

720

$e^{c r e w}$

$721 f_{t, p, w}^{\text {well }}$

722

$f_{t, p}^{p a d}$

723

$f_{t, p}^{p r e, i n}$

724

$f_{t, p, f}^{\text {source }}$

725
Indicates if at least one well is drilled in wellpad $\mathrm{p}$ in time period $\mathrm{t}$ with

fracturing crew c

Salt concentration on wellpad $\mathrm{p}$ in time period $\mathrm{t}, \mathrm{kg} \cdot \mathrm{kg}^{-1}$

Salt concentration in fracturing tanks on wellpad $\mathrm{p}$ in time period $\mathrm{t}, \mathrm{kg} \cdot \mathrm{kg}^{-1}$

Salt concentration of the inlets flows in fracturing tanks on wellpad $\mathrm{p}$ in time period $\mathrm{t}, \mathrm{kg} \cdot \mathrm{kg}^{-1}$

Drilling and production expenses, $\$$

Disposal expenses, \$

Storage freshwater and wastewater expenses, $\$$

Freshwater acquisition expenses, \$

Friction reducer expenses, $\$$

Transport expenses, $\$$

Onsite treatment expenses, $\$$

Centralized water treatment expenses, $\$$

Drilling and production expenses, \$

Moving crew expenses, \$

Flowrate of produced water on well $\mathrm{w}$ wellpad $\mathrm{p}$ in time period $\mathrm{t}, \mathrm{m}^{3} \cdot \mathrm{week}^{-1}$

Flowrate of produced water on wellpad $\mathrm{p}$ in time period $\mathrm{t}, \mathrm{m}^{3} \cdot \mathrm{week}^{-1}$

Onsite pretreatment inflow in wellpad $\mathrm{p}$ in time period $\mathrm{t}, \mathrm{m}^{3} \cdot \mathrm{week}^{-1}$

Flowrate of freshwater from natural source $\mathrm{f}$ to wellpad $\mathrm{p}$ in time period $\mathrm{t}$, $\mathrm{m}^{3} \cdot$ week $^{-1}$ 
A. Carrero-Parreño et al.

$726 f_{t, p}^{\text {on, fut }}$

$728 f_{t, p p, p}^{p a d, f w t}$

$730 f_{t, p}^{\text {on,des }}$

731

732

$734 f_{t, p}^{d e m}$

736

737

$738 f_{t, p}^{o n, i n}$

740

742

$744 f_{t, k}^{c w t, i n}$

745
Flowrate of desalinated water from onsite treatment to freshwater tanks in wellpad $\mathrm{p}$ in time period $\mathrm{t}, \mathrm{m}^{3} \cdot \mathrm{week}^{-1}$

Flowrate of desalinated water from wellpad pp to freshwater tanks in wellpad $\mathrm{p}$ in time period $\mathrm{t}, \mathrm{m}^{3} \cdot \mathrm{week}^{-1}$

Flowrate of freshwater used in hydraulic fracturing in wellpad $\mathrm{p}$ in time period $\mathrm{t}, \mathrm{m}^{3} \cdot \mathrm{week}^{-1}$

Flowrate of impaired water used in hydraulic fracturing in wellpad $\mathrm{p}$ in time period $\mathrm{t}, \mathrm{m}^{3} \cdot$ week $^{-1}$

Flowrate of water demand in wellpad $\mathrm{p}$ in time period $\mathrm{t}, \mathrm{m}^{3} \cdot \mathrm{week}^{-1}$ Onsite pretreatment outflow in wellpad $\mathrm{p}$ in time period $\mathrm{t}, \mathrm{m}^{3} \cdot \mathrm{week}^{-1}$ Slud flowrate after onsite desalination process in wellpad $\mathrm{p}$ in time period $\mathrm{t}$, $\mathrm{m}^{3} \cdot$ week $^{-1}$

Onsite desalination inflow in wellpad $\mathrm{p}$ in time period $\mathrm{t}, \mathrm{m}^{3} \cdot \mathrm{week}^{-1}$

$f_{t, p}^{\text {on,out }} \quad$ Onsite desalination outflow in wellpad $\mathrm{p}$ in time period $\mathrm{t}, \mathrm{m}^{3} \cdot \mathrm{week}^{-1}$

$f_{t, p, d}^{o n, b r i n e} \quad$ Brine flowrate after onsite desalination process in wellpad $\mathrm{p}$ in time period $\mathrm{t}$ $\mathrm{m}^{3} \cdot$ week $^{-1}$

$f_{t, p}^{o n, f r e s h} \quad$ Flowrate of desalinated water from onsite treatment on wellpad $\mathrm{p}$ in time period $\mathrm{t}$ sent to discharge, $\mathrm{m}^{3} \cdot \mathrm{week}^{-1}$

Inlet flow in centralized water treatment $\mathrm{k}$ in time period $\mathrm{t}, \mathrm{m}^{3} \cdot \mathrm{week}^{-1}$ $f_{t, k}^{c w t, o u t} \quad$ Outlet flow in centralized water treatment $\mathrm{k}$ in time period $\mathrm{t}, \mathrm{m}^{3} \cdot \mathrm{week}^{-1}$ 
A. Carrero-Parreño et al.

746

$f_{t, p, k}^{c w t, f w t}$

747

748

749

$750 \quad f_{t, p, s}^{i}$

$751 f_{t, p, s}^{o}$

$752 r^{g a s}$

753

754

755

756

757

758

759

760

761

762

763

764

765

766

767

768

$s t_{t, p, s}$

$y_{t, p, w}^{f b}$

Desalinated water from centralized water treatment $\mathrm{k}$ to freshwater tank on wellpad $\mathrm{p}$ in time period $\mathrm{t}, \mathrm{m}^{3} \cdot \mathrm{week}^{-1}$

$f_{t, k}^{c w t, d e s} \quad$ Desalinated water from centralized water treatment $\mathrm{k}$ to discharge in time period $\mathrm{t}, \mathrm{m}^{3} \cdot$ week $^{-1}$

Outlet flow in tank $\mathrm{s}$ in wellpad $\mathrm{p}$ in time period $\mathrm{t}, \mathrm{m}^{3} \cdot \mathrm{week}^{-1}$

Inlet flow in tank $\mathrm{s}$ in wellpad $\mathrm{p}$ in time period $\mathrm{t}, \mathrm{m}^{3} \cdot \mathrm{week}^{-1}$

Total gas revenue, \$

Level of water in tank type s on wellpad $\mathrm{p}$ in time period $\mathrm{t}, \mathrm{m}^{3}$

Indicates when the water starts to come out on well $\mathrm{w}$ on wellpad $\mathrm{p}$ in time period $t$

\section{REFERENCES}

(1) U.S. Energy Information Administration. International Energy Outlook 2016 http://www.eia.gov/outlooks (accessed Mar 12, 2018).

(2) Gao, J.; You, F. Design and Optimization of Shale Gas Energy Systems: Overview, Research Challenges, and Future Directions. Comput. Chem. Eng. 2017, 106, 699.

(3) U.S. Environmental Protection Agency. Technical Development Document For Effluent Limitations Guidelines and Standars for the Oil and Gas Extraction Point Source Category; Washington, DC, 2016.

(4) Holditch, S. A. Getting the Gas Out of the Ground. Chem. Eng. Prog. 2012.

(5) Onishi, V. C.; Carrero-Parreño, A.; Reyes-Labarta, J. A.; Ruiz-Femenia, R.; Salcedo-Díaz, R.; Fraga, E. S.; Caballero, J. A. Shale Gas Flowback Water 
A. Carrero-Parreño et al.

Desalination: Single vs Multiple-Effect Evaporation with Vapor Recompression Cycle and Thermal Integration. Desalination 2017, 404 (C), 230.

(6) Shaffer, D. L.; Arias Chavez, L. H.; Ben-sasson, M.; Romero-Vargas Castrillón, S.; Yip, N. Y.; Elimelech, M.; Sha, D. L.; Chavez, L. H. A.; Ben-sasson, M.; Castrillo, S. R. Desalination and Reuse of High-Salinity Shale Gas Produced Water: Drivers, Technologies, and Future Directions. Environ. Sci. Technol. 2013, $47(17), 9569$.

(7) Silva, T. L. S.; Morales-Torres, S.; Castro-Silva, S.; Figueiredo, J. L.; Silva, A. M. T. An Overview on Exploration and Environmental Impact of Unconventional Gas Sources and Treatment Options for Produced Water. J. Environ. Manage. 2017, 200, 511.

(8) Tavakkoli, S.; Lokare, O. R.; Vidic, R. D.; Khanna, V. A Techno-Economic Assessment of Membrane Distillation for Treatment of Marcellus Shale Produced Water. Desalination 2017, 416, 24.

(9) Mimouni, A.; Kuzmyak, N.; Oort, E. van; Sharma, M.; Katz, L. Compatibility of Hydraulic Fracturing Additives with High Salt Concentrations for Flowback Water Reuse. In World Environmental and Water Resources Congress 2015; pp 496-509.

(10) Paktinat, J.; Neil, B. O.; Tulissi, M.; Service, T. W. Case Studies: Improved Performance of High Brine Friction Reducers in Fracturing Shale Reserviors. SPE Int. 2011.

(11) Ruyle, B.; Fragachan, F. E. Quantifiable Costs Savings by Using $100 \%$ Raw Produced Water in Hydraulic Fracturing. SPE Int. 2015.

(12) Yang, L.; Grossmann, I. E.; Manno, J. Optimization Models for Shale Gas Water Management. AIChE J. 2014, 60 (10), 3490. 
A. Carrero-Parreño et al.

794 (13) Yang, L.; Grossmann, I. E.; Mauter, M. S.; Dilmore, R. M. Investment Optimization Model for Freshwater Acquisition and Wastewater Handling in Shale Gas Production. AIChE J. 2015, 61 (6), 1770.

(14) Bartholomew, T. V; Mauter, M. S. Multiobjective Optimization Model for Minimizing Cost and Environmental Impact in Shale Gas Water and Wastewater Management. ACS Sustain. Chem. Eng. 2016, 4 (7), 3728.

800

(15) Gao, J.; You, F. Optimal Design and Operations of Supply Chain Networks for 801 Water Management in Shale Gas Production: MILFP Model and Algorithms for

(16) Gao, J.; You, F. Shale Gas Supply Chain Design and Operations toward Better Economic and Life Cycle Environmental Performance: MINLP Model and Global Optimization Algorithm. ACS Sustain. Chem. Eng. 2015, 3 (7), 1282.

(17) Guerra, O. J.; Calderón, A. J.; Papageorgiou, L. G.; Siirola, J. J.; Reklaitis, G. V. An Optimization Framework for the Integration of Water Management and Shale Gas Supply Chain Design. Comput. Chem. Eng. 2016, 92, 230.

(18) Lira-Barragán, L. F.; Ponce-Ortega, J. M.; Guillén-Gosálbez, G.; El-Halwagi, M.

812 (19) Lira-Barragán, L. F.; Ponce-Ortega, J. M.; Serna-González, M.; El-Halwagi, M. M. Optimal Reuse of Flowback Wastewater in Hydraulic Fracturing Including Seasonal and Environmental Constraints. AIChE J. 2016, 62 (5).

815 (20) Drouven, M. G.; Grossmann, I. E. Optimization Models for Impaired Water 816 Management in Active Shale Gas Development Areas. J. Pet. Sci. Eng. 2017, 156, 817 983. 
A. Carrero-Parreño et al.

818 (21) Chen, Y.; He, L.; Guan, Y.; Lu, H.; Li, J. Life Cycle Assessment of Greenhouse Gas Emissions and Water-Energy Optimization for Shale Gas Supply Chain Planning Based on Multi-Level Approach: Case Study in Barnett, Marcellus, Fayetteville, and Haynesville Shales. Energy Convers. Manag. 2017, 134, 382.

(22) Chen, Y.; He, L.; Zhao, H.; Li, J. Energy-Environmental Implications of Shale Gas Extraction with Considering a Stochastic Decentralized Structure. Fuel 2018, $230,226$.

(23) He, L.; Chen, Y.; Zhao, H.; Tian, P.; Xue, Y.; Chen, L. Game-Based Analysis of Energy-Water Nexus for Identifying Environmental Impacts during Shale Gas Operations under Stochastic Input. Sci. Total Environ. 2018, 627, 1585.

(24) Zore, Ž.; Čuček, L.; Kravanja, Z. Syntheses of Sustainable Supply Networks with a New Composite Criterion - Sustainability Profit. Comput. Chem. Eng. 2017, $102,139$.

(25) Carrero-Parreño, A.; Onishi, V. C.; Salcedo-Díaz, R.; Ruiz-Femenia, R.; Fraga,

(26) Carrero-Parreño, A.; Onishi, V. C.; Ruiz-Femenia, R.; Salcedo-Díaz, R.; Flowback Water from Shale Gas Production. Ind. Eng. Chem. Res. 2017, 56 (15),

(27) Onishi, V. C.; Carrero-Parreño, A.; Reyes-Labarta, J. A.; Fraga, E. S.; Caballero, J. A. Desalination of Shale Gas Produced Water: A Rigorous Design Approach for Zero-Liquid Discharge Evaporation Systems. J. Clean. Prod. 2017, 140, 1399. 
A. Carrero-Parreño et al.

842 (28) Delft University of Technology. The Model of the Eco-costs/Value Ratio (EVR) http://www.ecocostsvalue.com (accessed Dec 1, 2017).

844 (29) Garth P. McCormick. Mathematical Programming Computability of Global Solutions to Factorable Nonconvex Programs: Part I - Convex Underestimating Problems. Math. Program. 1976, 10 (1), 147.

847 (30) Rosenthal, R. E. GAMS - A User' S Guide; GAMS; Development Corporation: Washington, DC, 2016.

(31) Gurobi Optimization, I. Gurobi Optimizer Reference Manual http://www.gurobi.com (accessed Mar 12, 2018).

(32) Duran, M. A.; Grossmann, I. E. An Outer-Approximation Algorithm for a Class of Mixed-Integer Nonlinear Programs. Math. Program. 1986, 36, 307.

(33) Drud, A. CONOPT: A GRG Code for Large Sparse Dynamic Nonlinear Optimization Problems. Math. Program. 1985, 31 (2), 153.

(34) United States Department of Labor. Usual Weekly Earnings of Wage and Salary Workers https://www.bls.gov/news.release/wkyeng.toc.htm (accessed Mar 12, 2018).

858

859

Table of Contents Graphic

860

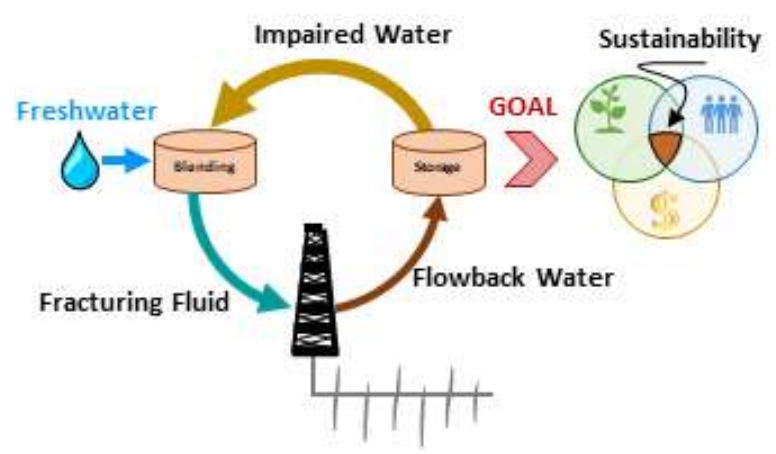


A. Carrero-Parreño et al.

864 The following tables (Tables S.1-S.4) details the parameters used in the mathematical

865 model for the case study: cost coefficients, model parameters, eco-cost and social 866 coefficients.

867

868

\section{Table S.1. Costs coefficient}

\begin{tabular}{|c|c|c|c|}
\hline Parameter & Value & Units & Ref \\
\hline Drilling cost $\left(\alpha^{\text {drill }}\right)$ & 270,000 & $\$$ & 1 \\
\hline Production cost ( $\left.\alpha^{\text {prod }}\right)$ & 0.014 & $\$ / \mathrm{m}^{3}$ & 1 \\
\hline Disposal cost $\left(\alpha_{d}^{d i s}\right)$ & $90-120$ & $\$ / \mathrm{m}^{3}$ & 2 \\
\hline Truck cost $\left(\alpha^{\text {truck }}\right)$ & 0.15 & $\$ / \mathrm{km} / \mathrm{m}^{3}$ & 2 \\
\hline Storage cost $\left(\alpha_{s}^{\text {sto }}\right)$ & 70 & $\$ /$ week/tank & $*$ \\
\hline Impoundment cost $\left(\alpha^{i m}\right)$ & 3.86 & $\$ / \mathrm{m}^{3}$ & 3 \\
\hline Pretreatment cost $\left(\alpha^{\text {reuse }}, \alpha^{\text {treat }}\right)$ & $0.8-2$ & $\$ / \mathrm{m}^{3}$ & 4 \\
\hline Desalination cost $\left(\alpha_{n}^{o n}\right)$ & $6-15$ & $\$ / \mathrm{m}^{3}$ & 5,6 \\
\hline Demobilize, mobilize and clean out $\operatorname{cost}\left(\beta_{n}^{\text {on }}\right)$ & 2,000 & \$/week & $*$ \\
\hline Centralized water treatment $\left(\alpha_{k}^{c w t}\right)$ & $42-84$ & $\$ / \mathrm{m}^{3}$ & 2 \\
\hline Demobilize, mobilize and clean out $\operatorname{cost}\left(\beta_{s}^{\text {sto }}\right)$ & 1,500 & $\$$ & $*$ \\
\hline Friction reducer cost $\left(\alpha^{f r}\right)$ & $0.18-0.30$ & $\$ / m^{3}$ & $*$ \\
\hline Freshwater withdrawal cost ( $\left.\alpha_{f}^{\text {source }}\right)$ & $1.76-3.5$ & $\$ / \mathrm{m}^{3}$ & 3 \\
\hline Moving crew cost $\left(\alpha^{\text {crew }}\right)$ & 83,000 & $\$$ & $*$ \\
\hline
\end{tabular}


A. Carrero-Parreño et al.

Table S.2. Model parameters

\begin{tabular}{|c|c|c|c|}
\hline Parameter & Value & Units & Ref \\
\hline$C S T_{S}$ & 60 & $\mathrm{~m}^{3}$ & $*$ \\
\hline$C_{t, p, w}^{w e l l}$ & $3,000-200,000$ & ppm & 7 \\
\hline$C^{c o n}$ & 300 & $\mathrm{~g} \mathrm{~kg}^{-1}$ & 5 \\
\hline$F_{n}^{o n, U P}$ & 4,000 & $\mathrm{~m}^{3}$ week $^{-1}$ & $*$ \\
\hline$F_{k}^{c w t, U P}$ & 16,700 & $\mathrm{~m}^{3}$ week $^{-1}$ & $*$ \\
\hline$N_{s}^{U P}$ & 100 & - & $*$ \\
\hline$N^{i m, U P}$ & 3 & - & * \\
\hline$N_{n}^{\text {on,UP }}$ & 3 & - & $*$ \\
\hline$V^{i m}$ & 120 & $\mathrm{~m}^{3}$ & $*$ \\
\hline$W D_{w}$ & $4,800-18,600$ & $\mathrm{~m}^{3}$ week $^{-1}$ & 7 \\
\hline$\tau_{w}$ & $1-5$ & weeks & 7 \\
\hline
\end{tabular}

872

*Provided by a shale gas company

873 
A. Carrero-Parreño et al.

Table S.3. Eco-cost coefficients ${ }^{8}$

\begin{tabular}{ccl}
\hline Raw material $\left(\mu_{r}\right)$ & Eco-cost & \multicolumn{1}{c}{ Interpretation } \\
\hline Freshwater & $0.19 € \mathrm{~m}^{-3}$ & water scarcity \\
\hline Products $\left(\mu_{g}\right)$ & Eco-cost & Interpretation \\
\hline Desalinated water to & $1 € \mathrm{~m}^{-3}$ & Water from drilling is treated \\
discharge & & and returned to natural resource \\
Desalinated water to & $1 € \mathrm{~m}^{-3}$ & and used for new drilling \\
reuse & & operations \\
Disposal water & $37 € \mathrm{~m}^{-3}$ & Disposal \\
Natural gas at extraction & $0.05 € \mathrm{~m}^{-3}$ & Natural gas extraction \\
\hline Transport $\left(\mu_{g}^{T}, \mu_{r}^{T}\right)$ & $\mathbf{E c o - c o s t}$ & Interpretation \\
\hline Transport & $0.01 € \mathrm{~m}^{-3} \mathrm{~km}^{-1}$ & Truck plus container \\
\hline & & \\
\hline & & \\
\hline
\end{tabular}

875

876

Table S.4. Social coefficients

\begin{tabular}{lccc}
\hline \multicolumn{1}{c}{ Parameter } & Value & Units & Ref \\
\hline$N^{\text {jobs }}$ & 145 & - & 9 \\
$S^{\text {Gross }}$ & 857 & $\$$ week $^{-1}$ & 10 \\
$S^{\text {Net }}$ & 685 & \$ week & 10,11 \\
$C^{\text {UNE,State }}$ & 125 & \$ week & 12 \\
$C^{\text {EMP,State }}$ & 12.5 & \$ week & 12 \\
$C^{\text {company }}$ & 6.5 & \$ week & 12 \\
\end{tabular}

877 
A. Carrero-Parreño et al.

\section{References}

880 (1) Gao, J.; You, F. Shale Gas Supply Chain Design and Operations toward Better

(2) Yang, L.; Grossmann, I. E.; Mauter, M. S.; Dilmore, R. M. Investment

Optimization Model for Freshwater Acquisition and Wastewater Handling in Shale Gas Production. AIChE J. 2015, 61 (6), 1770.

886

(3) Yang, L.; Grossmann, I. E.; Manno, J. Optimization Models for Shale Gas Water Management. AIChE J. 2014, 60 (10), 3490.

(4) Carrero-Parreño, A.; Onishi, V. C.; Salcedo-Díaz, R.; Ruiz-Femenia, R.; Fraga, E. 4386.

892

(5) Onishi, V. C.; Carrero-Parreño, A.; Reyes-Labarta, J. A.; Ruiz-Femenia, R.; Desalination: Single vs Multiple-Effect Evaporation with Vapor Recompression Cycle and Thermal Integration. Desalination 2017, 404 (C), 230.

(6) Carrero-Parreño, A.; Onishi, V. C.; Ruiz-Femenia, R.; Salcedo-Díaz, R.;

Caballero, J. A.; Reyes-labarta, J. A. Multistage Membrane Distillation for the Treatment of Shale Gas Flowback Water: Multi-Objective Optimization under Uncertainty. Comput. Aided Chem. Eng. 2017, 40, 571. 
A. Carrero-Parreño et al.

903 (8) Delft University of Technology. The Model of the Eco-costs/Value Ratio (EVR)

904 http://www.ecocostsvalue.com (accessed Dec 1, 2017).

905 (9) Petroleum Services Association of Canada. How many jobs does a single drilling

906 rig create and where

are they?

907 https://www.albertaoilmagazine.com/2015/05/drilling-rig-jobs/ (accessed Mar 12,

908 2018).

909 (10) United States Department of Labor. Usual Weekly Earnings of Wage and Salary

910 Workers https://www.bls.gov/news.release/wkyeng.toc.htm (accessed Mar 12, $9112018)$.

912 (11) Urban Institute \& Brookings Institution. Tax Policy Center 913 http://www.taxpolicycenter.org/taxvox (accessed Mar 12, 2018).

914 (12) Zore, Ž.; Čuček, L.; Kravanja, Z. Syntheses of Sustainable Supply Networks with 915 a New Composite Criterion - Sustainability Profit. Comput. Chem. Eng. 2017, 102,

916 139. 